\title{
Comparison of Ares I-X Wind-Tunnel Derived Buffet Environment with Flight Data
}

\author{
David J. Piatak $^{*} \quad$ Martin K. Sekula $^{\dagger}$ Russ D. Rausch ${ }^{\ddagger}$ \\ Aeroelasticity Branch / NASA Langley Research Center \\ Hampton, VA 23681
}

\begin{abstract}
The Ares I-X Flight Test Vehicle (FTV), launched in October 2009, carried with it over 243 buffet verification pressure sensors and was one of the most heavily instrumented launch vehicle flight tests. This flight test represented a unique opportunity for NASA and its partners to compare the wind-tunnel derived buffet environment with that measured during the flight of Ares I-X. It is necessary to define the launch vehicle buffet loads to ensure that structural components and vehicle subsystems possess adequate strength, stress, and fatigue margins when the vehicle structural dynamic response to buffet forcing functions are considered. Ares I-X buffet forcing functions were obtained via wind-tunnel testing of a rigid buffet model (RBM) instrumented with hundreds of unsteady pressure transducers designed to measure the buffet environment across the desired frequency range. This paper discusses the comparison of RBM and FTV buffet environments, including fluctuating pressure coefficient and normalized sectional buffet forcing function root-mean-square magnitudes, frequency content of power-spectral density functions, and force magnitudes of an alternating flow phenomena. Comparison of wind-tunnel model and flight test vehicle buffet environments show very good agreement with root-mean-square magnitudes of buffet forcing functions at the majority of vehicle stations. Spectra proved a challenge to compare because of different wind-tunnel and flight test conditions and data acquisition rates. However, meaningful and promising comparisons of buffet spectra are presented. Lastly, the buffet loads resulting from the transition of subsonic separated flow to supersonic attached flow were significantly over-predicted by wind-tunnel results.
\end{abstract}

\section{Notice to Readers}

The predicted performance and certain other features and characteristics of the Ares I-X launch vehicle is defined by the U.S. Government to be Sensitive But Unclassified (SBU). Therefore, details have been removed from all plots and figures.

\section{Nomenclature}

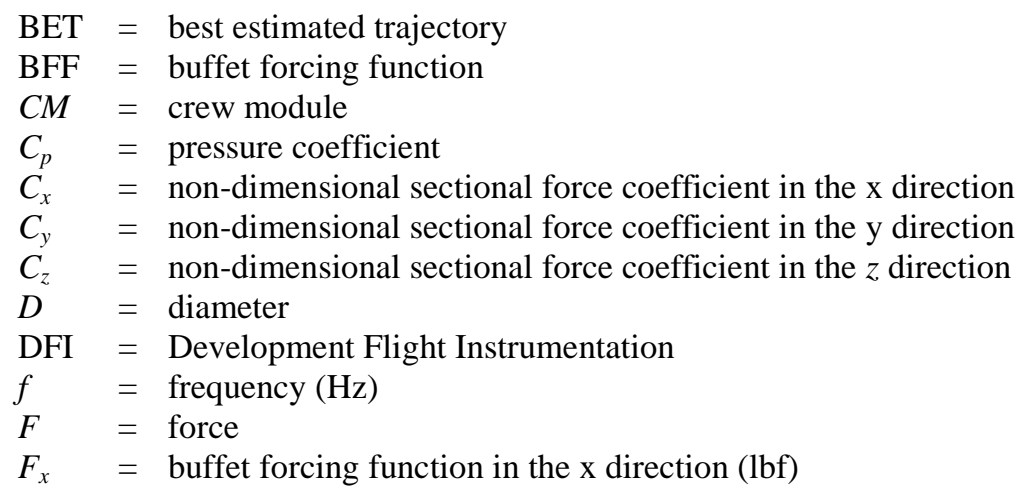

\footnotetext{
* Senior Aerospace Engineer, Aeroelasticity Branch, Mail Stop 340.

${ }^{\dagger}$ Senior Aerospace Engineer, Aeroelasticity Branch, Mail Stop 340.

${ }^{\ddagger}$ Senior Aerospace Engineer, Aeroelasticity Branch, Mail Stop 340.
} 


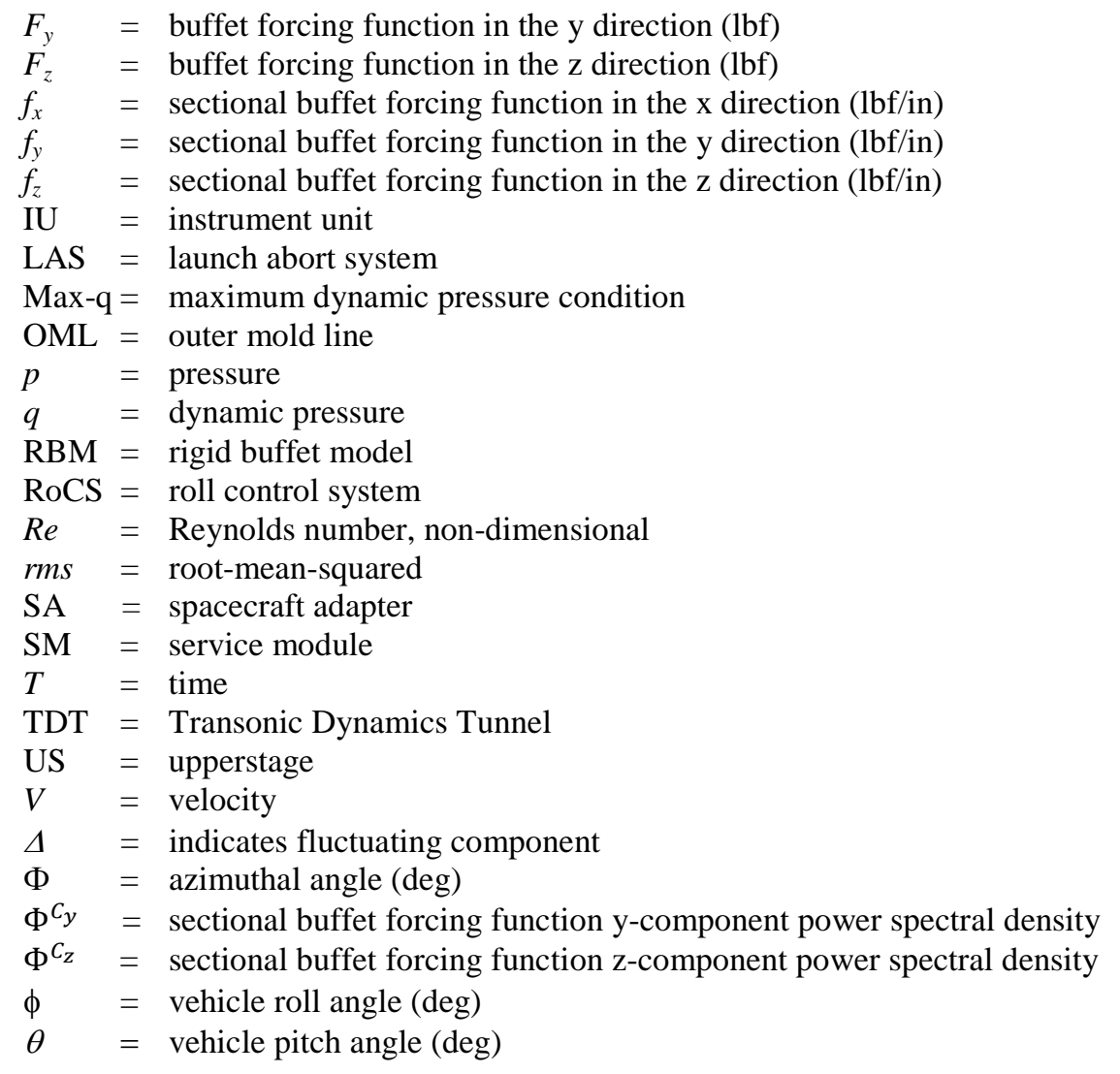

\section{Introduction}

$\mathbf{Q}$ uffet is a turbulent, unsteady aerodynamic phenomenon characterized by fluctuating pressures resulting from B flow-induced turbulence, flow separation, wake effects, and shock oscillations. These fluctuating pressures can produce significant loads on a launch vehicle and spacecraft during ascent to orbit. Fluctuating buffet pressure loads can excite a launch vehicle's bending modes and local shell/panel modes, as illustrated in Figure 1. The buffet environment is typically most extreme in the transonic regime as the vehicle approaches the speed of sound, but buffet loads can also be large at maximum dynamic pressure conditions. At transonic conditions in the trajectory, shocks form on the vehicle and can interact with other flow phenomena at locations where changes in the vehicle geometry occur. For buffet loads analysis of launch vehicles, the buffeting response is limited to the low frequency bending modes of the vehicle, typically below $60 \mathrm{~Hz}$. Higher frequency vibratory responses due to aeroacoustic

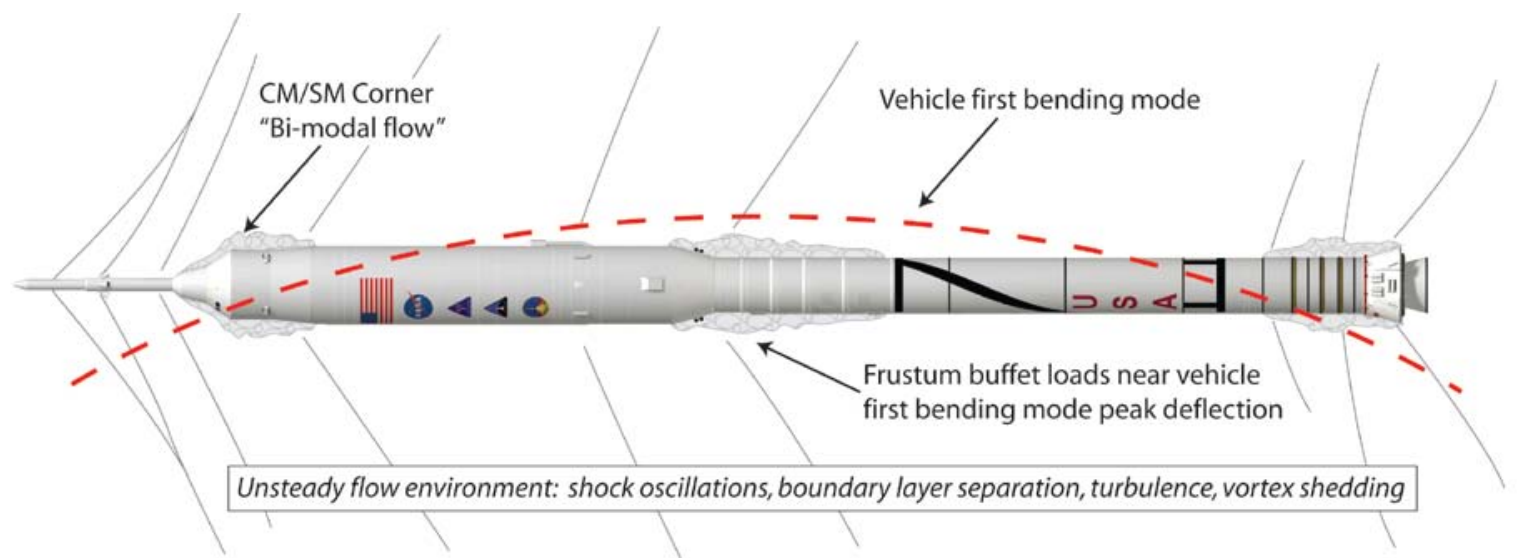

Figure 1. Unsteady flow environment for Ares I-X configuration. 
excitation fall under the regime of vibro-acoustic loads (refs. 1-3).

Buffet environments are usually expressed as forcing functions in a vehicle response analysis to evaluate buffet loads during ascent and are obtained via a buffet wind-tunnel test program. Even today, it is impractical to utilize computational fluid dynamics (CFD) to analyze launch vehicle buffet loads due to the wide range of flight conditions which must be considered and the requirement for time-accurate results. In late 2007, a 3.5\%-scale rigid buffet model (RBM) of the Ares I-X flight test vehicle (FTV) was tested at the NASA Langley Transonic Dynamics Tunnel (TDT) for the purpose of obtaining buffet forcing functions for Ares I-X structural loads analyses. The Ares I-X RBM test program was managed by Langley Research Center's Aeroelasticity Branch and acquired unsteady surface pressure data for Mach numbers ranging from 0.8 through 1.2 over a range of model attitudes of \pm 8 degrees angle of attack and \pm 180 degrees roll angle.

The flight of the Ares I-X FTV in October of 2009 represented an unprecedented opportunity to validate experimental buffet environments obtained from subscale, low Reynolds number wind-tunnel tests. Data recorded during the sub-orbital test flight of Ares I-X included 243 buffet verification fluctuating pressure measurements as part of the Development Flight Instrumentation (DFI) of which a majority of these pressure sensors were co-located with those measured on the RBM during wind-tunnel tests. This large number of DFI buffet pressure sensors allows not only individual pressure port wind-tunnel-to-flight comparisons, but also allows for integration of DFI buffet pressures to compare flight and wind-tunnel buffet forcing functions. This paper discusses the comparison of RBM and FTV buffet environments, including fluctuating pressure coefficient and sectional buffet forcing function root-mean-square magnitudes, frequency content of power-spectral density functions, and force magnitudes of an alternating flow phenomena.

\section{Test Program Description and Objecitves}

Buffet forcing functions obtained from testing of the Ares I-X RBM were utilized to define vehicle structural buffet loads and were included in the coupled loads analysis (CLA) of the Ares I-X FTV load cycle

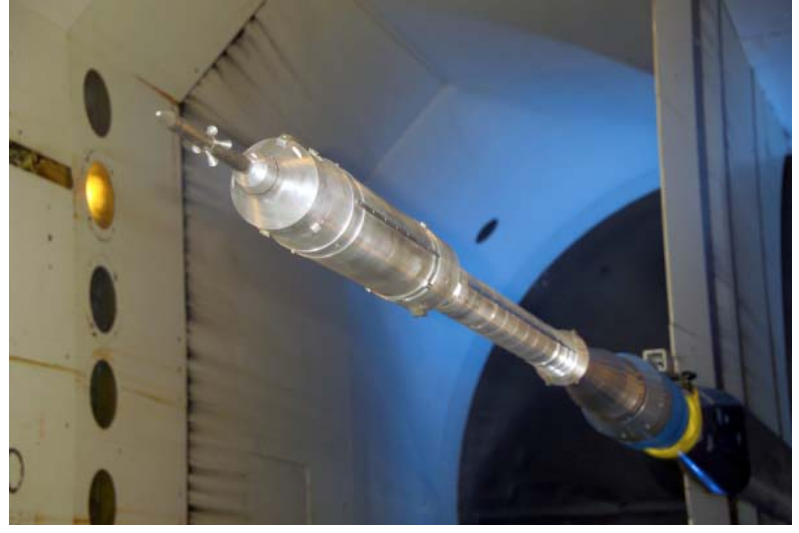

Figure 2. Ares I-X Rigid Buffet Model.

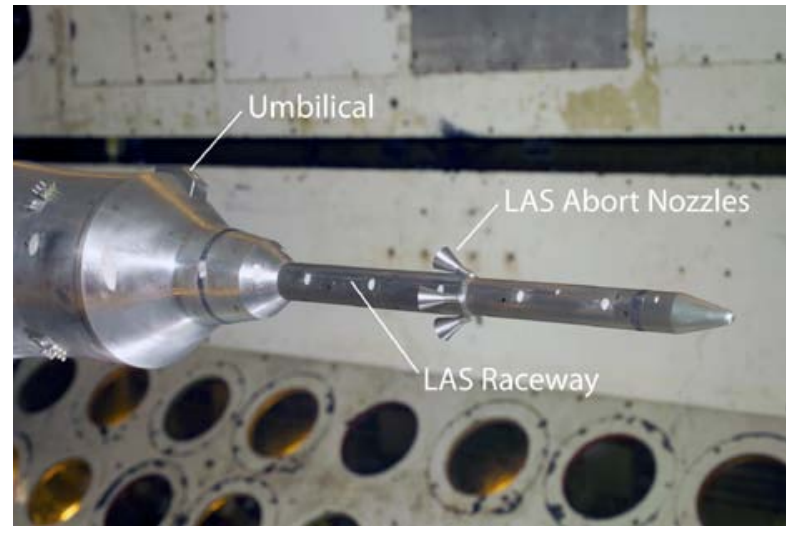

Figure 3. Ares I-X RBM launch abort system tower and crew module details.

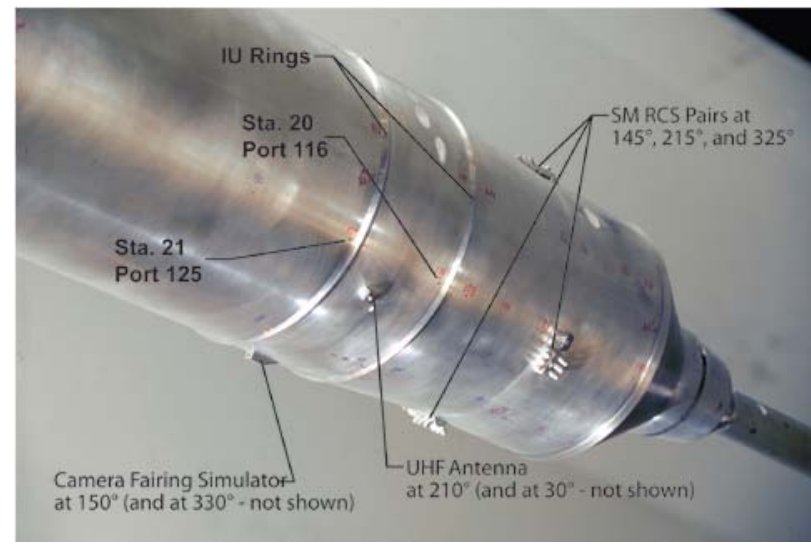

Figure 4. Ares I-X RBM upper stage, instrument unit, spacecraft adapter, and service module details. development. The coupled loads analysis combines forcing functions and loads from multiple disciplines (steady aerodynamic, buffet, vibroacoustic, thermal, and propulsion loads) which contribute to the overall loading of the vehicle at discrete points in the trajectory. The coupled loads analysis is performed during the development of the launch vehicle to ensure adequate structural load margins and vehicle structural integrity during the ascent trajectory. On launch day, CLA is also performed as part of the go/no-go decision-making process to take into account current winds-aloft conditions. For each of the load cases or forcing functions considered in the coupled loads analysis, an uncertainty factor is typically applied to represent the statistical uncertainty in the loads data. The 
uncertainty factor used in Ares I-X CLA was 1.25. It was anticipated that comparison and analysis of Ares I-X wind-tunnel and flight buffet forcing functions may allow for some relaxation of the uncertainty factors used in CLA for future flights. With the cancellation of the Constellation/Ares program, it is anticipated that these datasets will likely benefit future launch vehicle development. ${ }^{4}$

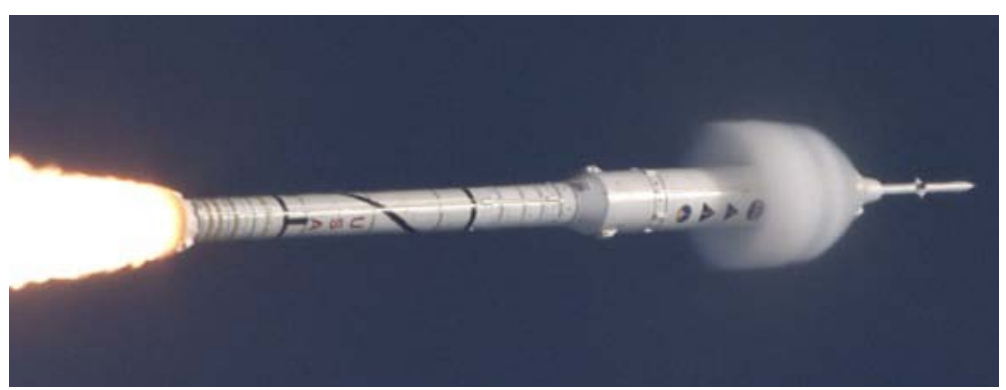

Figure 5. Ares I-X FTV at transonic conditions.

\section{A. Ares I-X Rigid Buffet Model Wind-Tunnel Test Program}

The primary objective of the Ares I-X buffet test program was to acquire time-correlated unsteady pressure data up to a minimum frequency of $60 \mathrm{~Hz}$ full-scale on a 3.5\%-scale Ares I-X model at transonic conditions. The RBM was tested at the NASA Langley Transonic Dynamics Tunnel which is a large, closed-circuit transonic wind tunnel with a 16-foot-by-16-foot slotted test section capable of reaching Mach 1.2 using a test medium of air or R-134a heavy gas at variable stagnation pressures less than or equal to one atmosphere. The Ares I-X rigid buffet model was 11.2 feet long and instrumented with 256 unsteady pressure transducers (differential pressure) with flush 0.040 inch diameter ports in rings of four or eight transducers at 52 stations along the length of the vehicle. Thirty-second time history records of pressure data at constant wind-tunnel conditions were acquired at a $12 \mathrm{KHz}$ sample rate. The sample rate and filter settings result in a model-scale bandwidth of $4.5 \mathrm{KHz}$ and a full-scale equivalent bandwidth of approximately $350 \mathrm{~Hz}$ (trajectory dependent). Tests were performed at Mach numbers between 0.5 and 1.2 with the focus on the transonic range up to dynamic pressures of 550 psf in an R-134a heavy gas test medium. The model had all relevant protuberances present and model pitch and roll orientations were set between \pm 8 degrees and \pm 180 degrees during testing to determine any buffet environment sensitivity to vehicle orientation. Figures 2 through 4 show the Ares I-X RBM in the TDT test section and details of the model outer mold line (OML), protuberances, and pressure port locations. The deliverable of this test program was a database of full-scale buffet forcing functions (BFFs) at key trajectory conditions for use in CLA. Buffet forcing functions consist of orthogonal force time histories $\left(F_{x}, F_{y}\right.$, and $F_{z}$ ) acting at the centerline of a launch vehicle. These time histories represent the unsteady aerodynamic loads acting on each segment of the model due to the buffet environment. The BFFs are obtained by integrating measured pressures from rings of transducers distributed along the longitudinal axis of the model. ${ }^{5-7}$

\section{B. Ares I-X Flight Test Vehicle Test Program}

The Ares I-X FTV was designed to serve as an ascent development flight test for the Ares I Crew Launch Vehicle (CLV) as part of NASA's, now-cancelled, Constellation Program. The primary FTV mission objectives were to flight test a dynamically and aerodynamically similar vehicle to the Ares I/Orion stack to validate first stage ascent flight control, aerodynamics, dynamics, stage separation sequencing, booster recovery, and to characterize roll torque requirements. ${ }^{8}$ Figure 5 shows the Ares I-X FTV during ascent flight through transonic conditions. An extensive array of Development Flight Instrumentation (DFI) sensors was installed on the vehicle to characterize the induced environments and structural loads experienced by the FTV during the ascent flight trajectory through first stage motor burnout and re-entry of first stage. To obtain the buffet environment on the FTV, 245 Kulite unsteady pressure transducers (absolute pressure) were installed

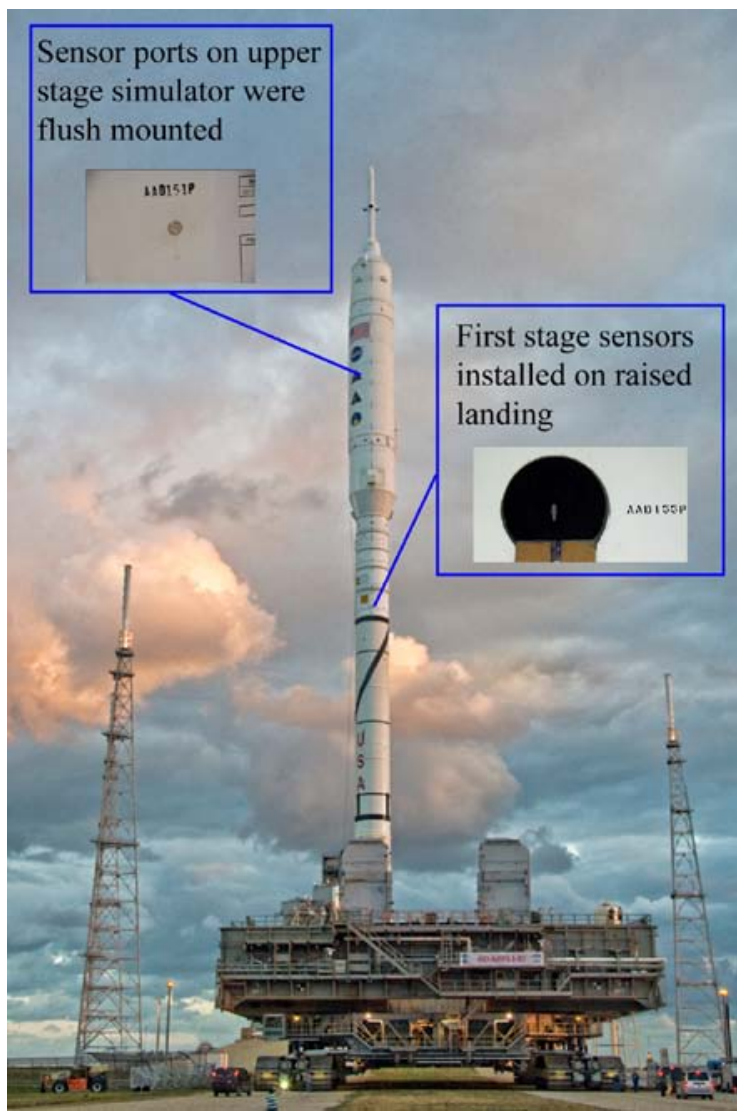

Figure 6. Ares I-X during rollout with sensor 
during assembly of the vehicle and the majority of the measurement locations coincided with those measured on the Ares I-X RBM to facilitate comparison of predicted and flight buffet environments. Figure 6 shows the FTV during rollout near Pad39B with details of the sensor installation noted. Buffet verification unsteady pressure sensors on upper-stage and spacecraft simulator were all flush mounted on the surface of the vehicle. Due to structural requirements and the presence of solid fuel, unsteady pressure sensors on the first stage were mounted outside of the OML within a raised "landing" in which the sensor and associated wiring were protected from the flow environment. Measured flight data was simultaneously down-linked to ground tracking stations via vehicle telemetry and recorded to flight data recorders in the first stage fifth segment simulator. Data was time-stamped to ensure timecorrelation and was recorded at a sample rate of $651.0417 \mathrm{~Hz}$. Flight data for buffet verification unsteady pressures were filtered at $130 \mathrm{~Hz}$ using an 8-pole butterworth filter to provide more-than-adequate frequency response to capture the buffet environment. ${ }^{9-10}$

\section{Ares I-X RBM and FTV Measurement Locations}

The distribution of unsteady pressure sensor stations for the RBM and FTV were guided by CFD predictions of $C_{p}$ and engineering judgement of expected regions of the vehicle which would have significant unsteady flow. The regions of the vehicle with a high percentage of measurement stations and high expected buffet environments include the forward part of vehicle (LAS, CM, SM, and SA) and the frustum. The RBM was instrumented with 256 transducers located at 43 stations in rings of 4 or 8 transducers. Similarly, the FTV was instrumented with 243 transducers at 45 stations in rings of 4 or 8 transducers with the majority of transducer locations on the FTV at identical or comparably identical locations to the RBM. Figure 7 presents the comparison of RBM and FTV measurement stations. Of the 45 measurement stations on the FTV, 32 were in common with the RBM (represented by green lines in Figure 7). Blue lines shown in Figure 7 represents transducer stations found only on the FTV while red lines represent stations found only on the RBM.

\section{Data Analysis}

The primary goal of this effort is to compare buffet environment predictions from the Ares I-X RBM wind-tunnel test to the buffet environment measured during the flight of Ares I-X FTV. Beyond the size of the test articles, many other parameters of the test environment differed between the RBM and FTV. Table 1 presents a comparison of wind-tunnel RBM and FTV dynamic pressure, velocity, and Reynolds number for a given trajectory Mach number. An order-of-magnitude difference in Reynolds number is seen in Table 1. The RBM was tested in a R-134a heavy gas test medium with a speed of sound half that of air which is evident when comparing velocities in Table 1 . The other difference inherent in the RBM and FTV data is the manner in which the data was acquired. The RBM data was acquired at steady flow conditions while FTV data was acquired at rapidly changing flight conditions according to the vehicle trajectory. These and other issues must be adequately addressed or considered in analyzing this data and drawing conclusions.

Of primary interest in analysis of the buffet environment are full-scale buffet forcing functions which consist of orthogonal centerline load time

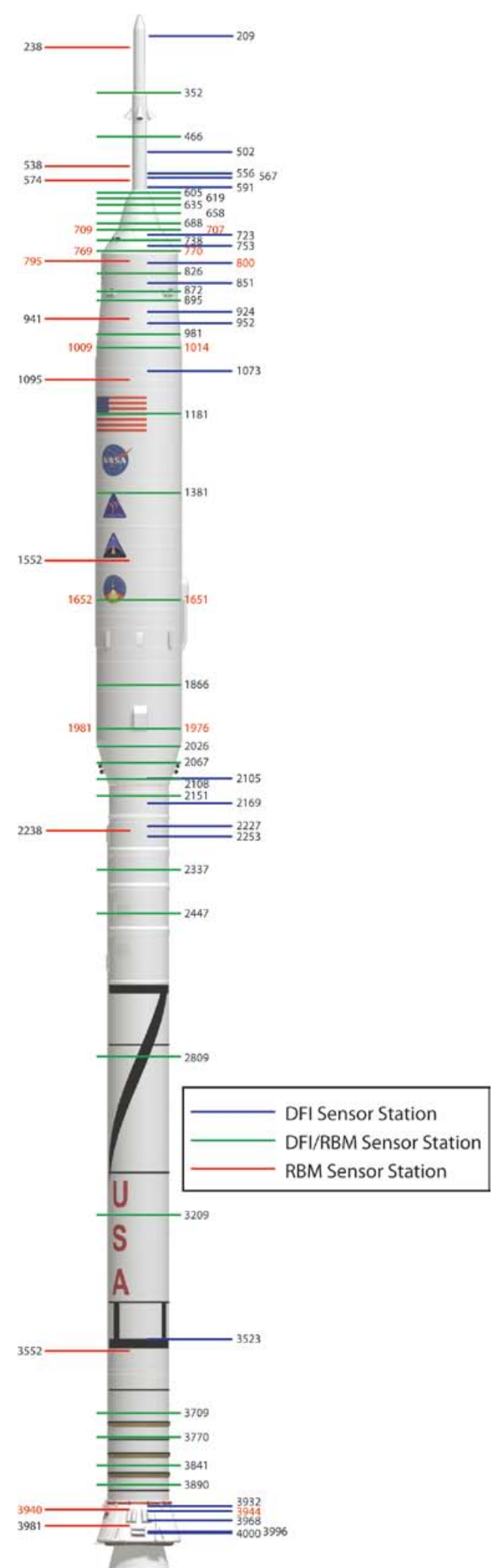

Figure 7. Ares I-X RBM and FTV measurement stations. 
histories. These forcing functions are obtained by integrating pressures at each vehicle station possessing a ring of transducers and has been performed on both RBM and FTV unsteady pressure data. Both force-type $\left(F_{x}, F_{y}, F_{z}: l b f\right)$ and sectional $\left(f_{x}, f_{y}, f_{z}:\right.$ lbf/in) BFFs were computed at each vehicle measurement station. Figure 8 illustrates sectional and force-type buffet forcing functions acting at the vehicle centerline that have been

Table 1. Comparison of RBM and FTV flow conditions.

\begin{tabular}{|c|c|c|c|c|c|c|}
\hline $\begin{array}{c}\text { Mach } \\
\text { Number }\end{array}$ & $\begin{array}{c}\text { RBM } \\
\mathbf{q}, \mathbf{p s f}\end{array}$ & $\begin{array}{c}\text { RBM } \\
\text { V, ft/s }\end{array}$ & $\begin{array}{c}\text { RBM } \\
\text { Reynolds Number }\end{array}$ & $\begin{array}{c}\text { FTV } \\
\mathbf{q}, \mathbf{p s f}\end{array}$ & $\begin{array}{c}\text { FTV } \\
\text { V, ft/s }\end{array}$ & $\begin{array}{c}\text { FTV } \\
\text { Reynolds Number }\end{array}$ \\
\hline \hline 0.5 & 199 & 278 & $2.37 \mathrm{E}+06$ & 306 & 562 & $3.54 \mathrm{E}+07$ \\
\hline 0.8 & 481 & 441 & $3.61 \mathrm{E}+06$ & 604 & 882 & $4.55 \mathrm{E}+07$ \\
\hline 0.9 & 480 & 499 & $3.18 \mathrm{E}+06$ & 687 & 983 & $4.72 \mathrm{E}+07$ \\
\hline 1.0 & 480 & 546 & $2.95 \mathrm{E}+06$ & 751 & 1081 & $4.77 \mathrm{E}+07$ \\
\hline 1.2 & 300 & 653 & $1.56 \mathrm{E}+06$ & 834 & 1265 & $4.71 \mathrm{E}+07$ \\
\hline
\end{tabular}
integrated from a ring of four unsteady pressures on a notional section of a launch vehicle. Note that in this figure, only $f_{y}, f_{z}, F_{y}$, and $F_{z}$ forcing functions exist because the pressure transducer rings are on a longitudinal segment of the vehicle that has a constant diameter along the segment. $F_{X}$ and $f_{x}$ is non-zero only on regions which are cone or frustum shaped where the diameter is changing along length of the vehicle segment. Buffet forcing function results presented in this paper will focus on sectional BFF.

\section{A. Ares I-X RBM Data Analysis Methods}

Model-scale time histories of pressure and force from the RBM must be scaled to full-scale quantities according to the Ares I-X flight trajectory conditions in order to be used within structural analyses and to compare to FTV results. Table 2 lists the pertinent scaling relationships used to scale quantities associated with the buffet environment analysis. For a given Mach number, full-scale flight conditions are interpolated from the FTV trajectory and are used to scale the magnitude and time-scale (sample rate) of the measured wind-tunnel RBM test data.

Besides integrating pressures to yield forcing functions and scaling the test data, there exists overconservatism (over-prediction) in the wind-tunnel derived buffet forcing functions which must be addressed. The assumption that measured pressure fluctuations over each transducer's defined zone of integration are fully correlated can result in buffet forcing functions that are over predicted and too conservative. This over-conservatism arises because the integration process assumes that, at any instant in time, the measured pressure is applied to the entire area of integration. In reality, the magnitude and phase of the fluctuating pressures change as the fluid moves down the vehicle and therefore the pressures do not act in unison across the integration area. The overconservatism can be amplified by increasing transducer separation, which increases the longitudinal extent of integration zones over which measured pressures are

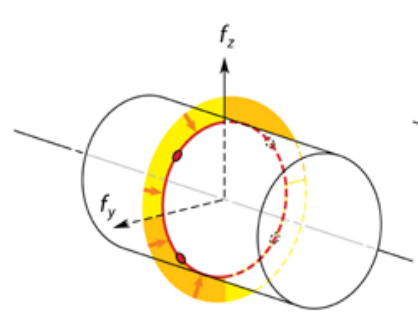

(a) Sectional load integration.

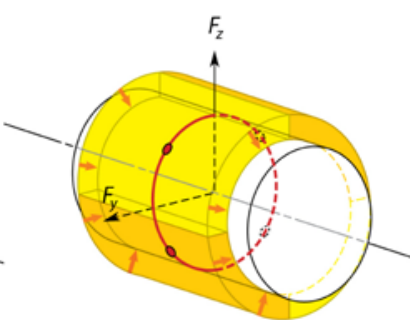

(b) Point load integration.

Figure 8. Integration of sectional and point load forcing functions acting at centerline of vehicle.

Table 2. Rigid buffet model scaling laws.

\begin{tabular}{|c|c|}
\hline $\begin{array}{c}\text { Quantity } \\
\text { to be } \\
\text { Scaled }\end{array}$ & Full scale to Model scale Relationship \\
\hline \hline Pressure & $p_{f s}=p_{m s} \frac{q_{f s}}{q_{m s}}$ \\
\hline Force & $F_{f s}=F_{m s} \frac{q_{f s}}{q_{m s}}\left(\frac{D_{f s}}{D_{m s}}\right)^{2}$ \\
\hline Time & $T_{f s}=T_{m s} \frac{D_{f s}}{D_{m s}} \frac{V_{m s}}{V_{f s}}$ \\
\hline Frequency & $f_{f s}=f_{m s} \frac{D_{m s}}{D_{f s}} \frac{V_{f s}}{V_{m s}}$ \\
\hline
\end{tabular}
integrated (and assumed fully correlated over that zonal area).

The limitations of buffet pressure model sensor distribution and their impact on the over-prediction of buffet loads as discussed above leads to the use of sensor-to-sensor correlation magnitudes for reducing the overly conservative predictions of buffet environments. The level of correlation between two transducer measurements can be quantified by calculating the coherence between the two signals. The coherence between two transducer measurements is a function of frequency, and the coherence values can range between zero and one. The coherence decreases exponentially with increasing transducer separation distance, signaling that the measured pressure time histories are becoming less correlated. This observation is important in buffet load analysis because the more 
correlated the transducer signals are, the greater the effective loading. In other words, as the transducer spacing increases and the coherence decreases, it becomes more inaccurate to integrate the measured pressures over the entire transducer zonal area. A technique based on longitudinal coherence is employed in the present analysis to reduce this over-conservatism, thereby avoiding unrealistically high predicted buffet loads which would thus improperly reduce the vehicle structural design margins. Azimuthal coherence and reduction of the azimuthal integration arc length were not considered because some degree of conservatism was desired. The method was developed based on a technique used by Aerospace Corporation in their buffet analysis of previous launch vehicles. This method for reducing over-conservatism in the buffet forcing functions is a multi-step process involving the identification of regions based on flow characteristics, estimation of flow coherence, calculation of the knockdown factors, and the application of these knockdown factors to the BFFs. ${ }^{5,6}$

\section{B. Ares I-X FTV Data Analysis Methods}

Following the flight of Ares I-X FTV in October 2009, DFI time history data was retrieved from on-board flight data recorders and down-loaded to the Huntsville Operations Support Center (HOSC). ${ }^{11}$ Buffet verification pressure channel data was obtained via the HOSC and converted to a MATLAB format and merged with the final Ares I-X best estimated trajectory (BET) to facilitate data analysis. ${ }^{12}$ Flight data consisted of unsteady pressures measured at 243 locations on the surface of the vehicle. Pressure coefficient time histories were computed using the final BET parameters and pressures were integrated to yield force and sectional buffet forcing functions. In order to compare flight test results to RBM wind-tunnel results, quasi-steady 1-second windows of flight data were extracted from the full time record and were centered at cardinal Mach numbers from the BET trajectory. Each one-second window was detrended to remove linear trends due to changing trajectory conditions and filtered using a bandpass filter ( 0.5 $\mathrm{Hz}$ to $60 \mathrm{~Hz}$ ) such that the buffet bandwidth was isolated. The window Mach number is the average Mach number within the 1-second window and Mach variation within the window is approximately 0.02 . Table 3 lists the average window cardinal Mach number, dynamic pressure, window trajectory time, window Mach number range, and flight event notes which may impact measured data. These quasi-steady 1-second windows at cardinal Mach numbers were therefore used to compute mean and root-mean-square (rms) results of $C_{p}$ and BFFs for direct comparison to RBM wind-tunnel results.

Table 3. Mach and BET time ranges for 1-second quasi-steady windows.

\begin{tabular}{|c|c|c|c|c|c|c|c|}
\hline \multirow[t]{2}{*}{$\begin{array}{l}\text { Cardinal } \\
\text { Mach }\end{array}$} & \multirow[t]{2}{*}{$\begin{array}{c}\text { Dynamic } \\
\text { Pressure, } \\
\text { psf }\end{array}$} & \multirow{2}{*}{$\begin{array}{c}\text { Window } \\
\text { Center } \\
\text { Trajectory } \\
\text { Time, secs } \\
\text { from T-Zero } \\
\end{array}$} & \multicolumn{2}{|c|}{$\begin{array}{l}\text { Mach Number } \\
\text { Range }\end{array}$} & \multicolumn{2}{|c|}{$\begin{array}{l}\text { Best Estimated } \\
\text { Trajectory Time } \\
\text { Range, secs }\end{array}$} & \multirow[t]{2}{*}{ Flight Event Notes } \\
\hline & & & Start & End & Start & End & \\
\hline 0.80 & 603.5 & 32.027 & 0.785 & 0.815 & 31.528 & 32.528 & $\begin{array}{c}\text { RoCS firing event begins } \\
\text { at } 32.06\end{array}$ \\
\hline 0.85 & 646.7 & 33.73 & 0.836 & 0.865 & 33.232 & 34.232 & $\begin{array}{l}\text { RoCS firing event; TVC } \\
\text { PTI begins at } 34.00\end{array}$ \\
\hline 0.90 & 686.5 & 35.43 & 0.886 & 0.913 & 34.934 & 35.934 & $\begin{array}{l}\text { RoCS firing event; Bi- } \\
\text { modal event at Mach } 0.91\end{array}$ \\
\hline 0.95 & 719.2 & 37.25 & 0.936 & 0.964 & 36.758 & 37.758 & $\begin{array}{l}\text { RoCS firing event ends at } \\
37.10\end{array}$ \\
\hline 1.10 & 798.0 & 42.41 & 1.084 & 1.115 & 41.913 & 42.913 & TVC PTI ends at 44.00 \\
\hline 1.20 & 832.1 & 45.68 & 1.183 & 1.215 & 45.192 & 46.192 & \\
\hline
\end{tabular}

\section{Wind-Tunnel and Flight Buffet Environment Results}

Comparisons of mean pressure coefficient and fluctuating pressure coefficient rms magnitudes $\left(\Delta C_{p, r m s}\right)$ are presented in this section for Ares I-X RBM wind-tunnel and FTV flight results. Root-mean-square magnitudes of 
RBM and FTV pressure time histories have had a $0.5-60 \mathrm{~Hz}$ filter applied to ensure results represent the identical full-scale bandwidth.

\section{A. Fluctuating Pressure Coefficient Root-Mean-Square Levels}

One second windows of FTV DFI flight data centered at cardinal Mach numbers were bandpass filtered between $0.5 \mathrm{~Hz}$ and $60 \mathrm{~Hz}$ and detrended to remove linear trends due to changing trajectory conditions. These windowed data were used to compute quasi-steady fluctuating pressure coefficient rms values $\left(\Delta C_{p, r m s}\right)$ at the window cardinal Mach number. RBM wind-tunnel data was similarly bandpass filtered to provide applicable comparisons. Figure 9 through Figure 16 present quasi-steady DFI flight $\Delta C_{p, r m s}$ compared to RBM results for Mach numbers of 0.85, $0.90,0.95$, and 1.2. At the majority of vehicle stations, very good comparisons between preflight wind-tunnel RBM and FTV DFI $\Delta C_{p, r m s}$ results are shown. In general, RBM wind-tunnel $\Delta C_{p, r m s}$ levels are slightly higher (more conservative) than FTV levels. In Figure 11 and Figure 12, large fluctuating pressure coefficient rms magnitudes are noted in both FTV and RBM data at the crew module and service module interface. These high rms magnitudes arise from a change in flow state in the vicinity of Mach 0.90 due to the sharp corner/shoulder at the crew module/service module. When observed in the wind tunnel, this flow phenomenon is referred to as alternating flow because the flowfield at the corner alternates rapidly between subsonic separated flow and supersonic attached flow near Mach 0.90 at constant wind-tunnel conditions. At rapidly changing flight conditions, this flow phenomenon occurs as a rapid, but azimuthally asymmetric change in flow state. Figure 17 and Figure 18 present Ares I-X FTV DFI $\Delta C_{p, r m s}$ values for Mach numbers of $1.20,1.44,2.00,3.00,4.00$, and 4.50. Although $\Delta C_{p, r m s}$ levels are relatively low at Mach 1.2, levels on the FTV are shown to rise to moderate levels at the Mach 1.44 maximum dynamic pressure condition in vicinity of crew module to service module interface and frustum. Beyond Mach 1.44, $\Delta C_{p, r m s}$ are seen to remain at moderate levels in vicinity of CM/SM interface.

\section{B. Normalized Sectional Buffet Forcing Functions}

Normalized sectional buffet forcing function $\left(C_{x, y, z}\right)$ trends in FTV and RBM data are compared in this section. Fluctuating pressures from 1-second windows of FTV data (quasi-steady flight condition assumption) and 30-second records of RBM data have been integrated to yield orthogonal sectional forcing functions (lbf/in) at centerline stations along the length of vehicle. The BFFs have been band-pass filtered to focus on buffet bandwidth (0.5$60 \mathrm{~Hz}$ ) and the root-mean-squared values at each station computed to allow for comparison of buffet environments from the flight test and wind-tunnel test. Figure 19 through Figure 24 present comparisons of BFF rms magnitudes at Mach numbers of 0.80, 0.85, 0.90, 0.95, 1.10, and 1.20. In general, wind-tunnel RBM and FTV flight BFF rms magnitudes compared very well with the wind-tunnel results tending to bound FTV magnitudes by reasonable margins. Buffet forcing function rms magnitudes are shown to peak within the transonic flight regime (approx. Mach 0.90). The BFFs at Mach 1.20 presented in Figure 24 are significantly less than those at transonic conditions. Given that additional factors of safety are applied to BFFs prior to buffet loads analysis and coupled loads analysis, it is assumed that adequate margins on buffet loads were present to allow for statistical outliers. However, a single flight test is not statistically significant to warrant modifying buffet loads and CLA methodologies. Because the Mach number at which maximum dynamic pressure occurred $\left(M_{\max -q}=1.67\right)$ was beyond the capabilities of the TDT, RBM data from Mach 1.2 was scaled to max-q flight conditions and was used in Ares I-X buffet loads analysis. Figure 25 presents the comparison of Mach 1.2 RBM wind-tunnel BFFs scaled to Mach 1.67 FTV max-q flight conditions and indicates that this methodology was a reasonable assumption and resulted in BFF rms magnitudes that were representative of what was measured in flight at max-q.

\section{Sectional Buffet Forcing Function Spectrograms}

Root-mean-square magnitudes provide only an indication of the total intensity of fluctuations in the BFFs across the buffet bandwidth and no indication of specific frequency content which is also important to buffet loads analysis. Figure 26 through Figure 28 present wideband spectrograms of FTV sectional buffet forcing function $\left(f_{y}\right)$ for stations 466, 591, 770, 800, 851, 980, 1380, 1975, 2067, 2169, 2809, and 3770 of the Ares I-X FTV. These spectrograms are computed from FTV DFI data and a moving window is applied which moves through the timeseries data and thus changing trajectory flight conditions. BFFs have not been bandpass-filtered prior to computation of spectrograms. For each window of flight data, a power spectral density is computed and plotted as a color intensity at the window center time/Mach on the figures presented. Wind-tunnel data is acquired at constant flow conditions and does not lend itself to examination in a spectrogram. However, spectrograms presented can provide insight into the changing frequency content of the buffet forcing functions during rapidly changing flight conditions. Figure 26 through Figure 28 reveal many spectral characteristics of the buffet flow environment of Ares 
I-X. Figure 26 clearly shows the Strouhal shedding frequency content in the wake of the launch abort system (LAS) nozzles at stations 466 and 770 inches. This Strouhal shedding frequency is seen to linearly increase with Mach number and velocity as expected. Also seen in Figure 26 is evidence of the bi-modal flow switch from subsonic separated flow to supersonic attached flow at the crew module to service module interface (cone/cylinder shoulder). Figure 27 shows significant evidence of the change in frequency content at the bi-modal change in flow state phenomenon at Mach 0.91 on the service module and spacecraft adapter and also shows evidence of firing of the RoCS motors. Frequency content in spectrograms of Figure 28 for the first stage is dominated by broadband noise due to engine noise reflected off the ground in the first ten seconds of flight.

\section{Sectional Buffet Forcing Function Power Spectral Densities}

The comparison of subsonic and supersonic examples of the power spectral density for sectional buffet forcing functions of FTV and RBM test data are presented in Figure 29 and Figure 30. The BFF time histories have not been bandpass filtered prior to computation of the PSDs. Due to the short amount of time spent in the vicinity of each Mach number and the quasi-steady 1-second window analysis assumption, FTV data PSDs have significantly fewer spectral lines when compared to RBM test data which consisted of 433-seconds of full-scale equivalent data at steady wind-tunnel conditions. Therefore it is difficult to draw conclusions with regard to frequency content comparisons of RBM and FTV test data. However, meaningful and promising comparisons of buffet spectra are presented in these figures. Results for Mach 0.85 are compared in Figure 29 at the crew module (station 770), spacecraft adapter (station 981), and first stage (station 3770) on the Ares I-X vehicle. The LAS nozzle vortex shedding frequency content at approximately $112 \mathrm{~Hz}$ is clearly shown in Figure 29 on the crew module and reasonable comparison between FTV and RBM spectral content is seen, considering the differences in time history lengths. Power spectral densities of sectional BFF at Mach 0.85 on the spacecraft adapter exhibit broadband frequency content out to 50-60 Hz with marked decrease in PSD magnitudes beyond $60 \mathrm{~Hz}$ and PSDs in Figure 29 for the first stage first motor segment show quite low and flat frequency content. Figure 30 presents PSD magnitudes on the crew module, service module, and first stage motor segment one for a Mach number of 1.2. Low frequency content in RBM data is noted in Figure 30 on the crew and service modules between 0.5 and $2 \mathrm{~Hz}$. Frequency content on the first stage motor segment at Mach 1.2 is at a relatively low magnitude and relatively flat.

\section{E. Transonic Alternating Flow}

At transonic conditions during ascent, the flow at expansion corners created by vehicle geometry changes such as cone-cylinder junctions can trigger a rapid transition of flow from a subsonic to a supersonic flow state. This rapid transition creates a large, asymmetric, and abrupt pressure change aft of the cone-cylinder junction. When integrated around the vehicle circumference, this pressure change can result in an impulsive and potentially significant load which must be considered in structural analyses and guidance/navigation. Within a critical Mach number range, the steady flow conditions of wind-tunnel testing causes this transonic event to manifest itself as an alternating flow separation and attachment phenomenon where the flow fluctuates between a separated subsonic flow and an attached supersonic flow at the cone-cylinder junction. The Ares I-X RBM data indicates that conditions conducive to the onset of alternating flow occur at Mach 0.90, resulting in pressure time histories that resemble a random, fluctuating square-wave as the flow rapidly alternates between the two flow states shown in the RBM shadowgraphs in Figure 31. When RBM pressures are integrated around the vehicle circumference, these azimuthally asymmetric pressure fluctuations create large buffet loads which also resemble square waves. The multiple occurrence of these loads is not representative of what happens in flight. It is believed that the rapidly changing flight trajectory conditions will result in only a single impulsive load event as the flow transitions from separated subsonic to attached supersonic flow conditions at a critical Mach number (between 0.88 and 0.92 for Ares I-X). Thus, a great deal of analysis effort was expended to determine the single worst-case alternating flow event from RBM test data and analytically represent this loading event time history in a buffet forcing function. ${ }^{7}$

An event equivalent to the RBM alternating flow condition was observed by DFI pressure sensors during the flight of the Ares I-X FTV. Figure 32 presents time histories of FTV pressure measurements during the first 60 seconds of flight at station 800 just down-stream of cone-cylinder junction and clearly shows a flow transition between subonic and supersonic conditions at Mach 0.91 . As expected, only a single transition event is noted. It should be noted that the event did not occur simultaneously at each transducer, resulting in a net load when these FTV pressures are integrated around the vehicle circumference. Figure 33 compares the FTV integrated load to the wind-tunnel derived Mach 0.9 alternating flow BFF. It was found that the RBM-derived BFF significantly overpredicted the load magnitude by nearly 200 percent. The duration of the pulse was also overpredicted by RBM wind-tunnel test results and analysis as indicated by the yellow highlighted regions in Figure 33. The direction of the pulse was predicted to be at approximately 60 degrees based on wind-tunnel test results. Flight test results 
indicate that the pulse load is initially applied at the -150 degree azimuth direction and changes to 60 degrees azimuth.

The transition of the flow from subsonic separated flow to supersonic attached flow downstream of the conecylinder expansion corner is highly dependent on the flow conditions. This flow phenomenon is influenced by factors such as vehicle geometry, vehicle attitude, atmospheric conditions, and the flight trajectory. The RBMderived impulsive load was based on a worst-case scenario, which was measured at $\alpha=1^{\circ}$ and $\beta=0^{\circ}$. The best estimated trajectory of the Ares I-X FTV at the time of the flow transition was approximately $\alpha=0.2^{\circ}$ and $\beta=0.9^{\circ}$. This difference in the vehicle attitude with respect to free stream velocity may, in part, explain the differences noted in Figure 33. Additionally, a single flight test result does not represent a statistically significant reason to modify the RBM-derived BFF for the alternating flow impulsive load for future Ares structural load cycles.

\section{Conclusions}

The buffet environment of the Ares I-X Flight Test Vehicle (FTV) has been compared to pre-fight predictions obtained from wind-tunnel testing of a 3.5\%-scale Rigid Buffet Model (RBM). The flight test acquired data using a significant number of unsteady pressure sensors during its ascent and many of these sensors were positioned at identical locations as those on the RBM. The databases of buffet environment unsteady pressures from Ares I-X FTV and RBM represent a significant opportunity to improve the understanding of the development of launch vehicle buffet forcing functions, to assess the uncertainty in buffet forcing functions, and to improve understanding of the alternating flow buffet environment. The following broad conclusions have been observed from this work:

1. FTV and RBM buffet environment root-mean-squared magnitudes of pressure coefficients and buffet forcing functions $\left(\Delta C_{p, r m s}\right.$ and $\left.\Delta C_{x y z, r m s}\right)$ compare quite well with RBM pre-test predictions. Rigid buffet model rms magnitudes are observed to be typically greater than FTV flight measurements (conservative).

2. Spectrograms of FTV buffet pressure data reveal varying spectral content with time and trajectory conditions. Launch abort system nozzle Strouhal shedding frequency is clearly seen in addition to other flow phenomena.

3. Power spectral density comparisons of FTV and RBM sectional buffet forcing functions reveal the difficulty of comparing averaged spectral content of time records with large differences in record length and scan rate. Provided these challenges, reasonable comparisons between wind-tunnel and flight test spectral contect has been shown.

4. The flow transition from subsonic separated to supersonic attached flow was observed during the flight of Ares I-X at Mach 0.91 and the resulting impulsive load magnitude was computed from unsteady pressure sensor data. The observed FTV alternating flow impulsive load was compared to pre-test RBM-derived predictions and found to be significantly less than predictions (conservative). However, trajectory conditions (vehicle orientation, velocity, gusts) at Mach 0.91 may significantly vary with each flight which suggests that reducing predicted magnitudes of the alternating flow pulse load based on a single test flight is not prudent, given that the phenomenon is sensitive to flight conditions.

\section{Acknowledgements}

The authors would like to thank Dr. Craig Streett of the Computational Aerosciences Branch at NASA Langley and Drs. Shin-Hsing Chen, James Canino, and Brian Sako of the Aerospace Corporation for their help in the analysis of the Ares I-X Rigid Buffet Model data. Technical leads and advocates for Ares I-X DFI instrumentation were crucial the the flight's test success and include Dominic R. Trombetta, Bradley L. Crawford, Larry Huebner, and David M. Schuster. The authors would also like to acknowledge the Ares Project Office at NASA Langley for their support of this work.

\section{References}

1. Jones, George W., Foughner, Jerome T., Jr., "Investigation of Buffet Pressures on Models of Large Manned Launch Vehicle Configurations”. NASA TN-D-1663, May 1963.

2. Rainey, Gerald A., "Progress on the Launch-Vehicle Buffeting Problem". Journal of Spacecraft and Rockets, Volume 2, Number 3, May-June 1965. 
3. Cole, Henry A., Jr.; Erickson, A. L.; and Rainey, A. G.: "Buffeting During Atmospheric Ascent”. NASA SP8001, 1963, Revised November 1970.

4. Kabe, A.M., "Time Domain Buffet Loads Analysis”. The Aerospace Corporation Report Number TOR2007(2209)-6078. November 17, 2006.

5. Piatak, D. J., et al, “Test Summary Document for the 3.5 Percent Ares I-X Rigid Buffet Model”. ARES-AE-TA0002, Version 1.0, July 11, 2008.

6. Piatak, D.J., Sekula, M.K., and Rausch, R.D., "Ares Launch Vehicle Transonic Buffet Testing and Analysis Techniques”. AIAA Paper No. 2010-4369. Presented at the $28^{\text {th }}$ Applied Aerodynamics Conference, Chicago, IL, 28 June - 1 July, 2010.

7. Sekula, M.K., Piatak, D.J., Rausch, R.D., “Analysis of a Transonic Alternating Flow Phenomenon Observed during Ares Crew Launch Vehicle Wind Tunnel Tests”. AIAA 2010-4370. Presented at the $28^{\text {th }}$ AIAA Applied Aerodynamics Conference, Chicago, Illinois, 28 June - 1 July 2010.

8. “Constellation Program Ares I-X Flight Test Plan”. CxP Revision B. Release Date: December 19, 2007.

9. Rausch, R.D., Piatak, D.J., et. al., "Comparison of Preflight Buffet Environment and Aeroelastic Solutions with Flight Data”. AIX-TAR-ARO0005, Revision 1.0, Release Date: December, 212010.

10. “Ares I-X Development Flight Instrumentation Measurement List”, AI1-SYS-DFI, As-built Version, February, 2010.

11. Ares I-X Development Flight Instrumentation Flight Data. Huntsville Operations Support Center (HOSC) CXP:ARS1:Flight:0015.

12. Ares I-X Flight Test Vehicle Final Best Estimated Trajectory. A1X_final_BET_26April2010. 

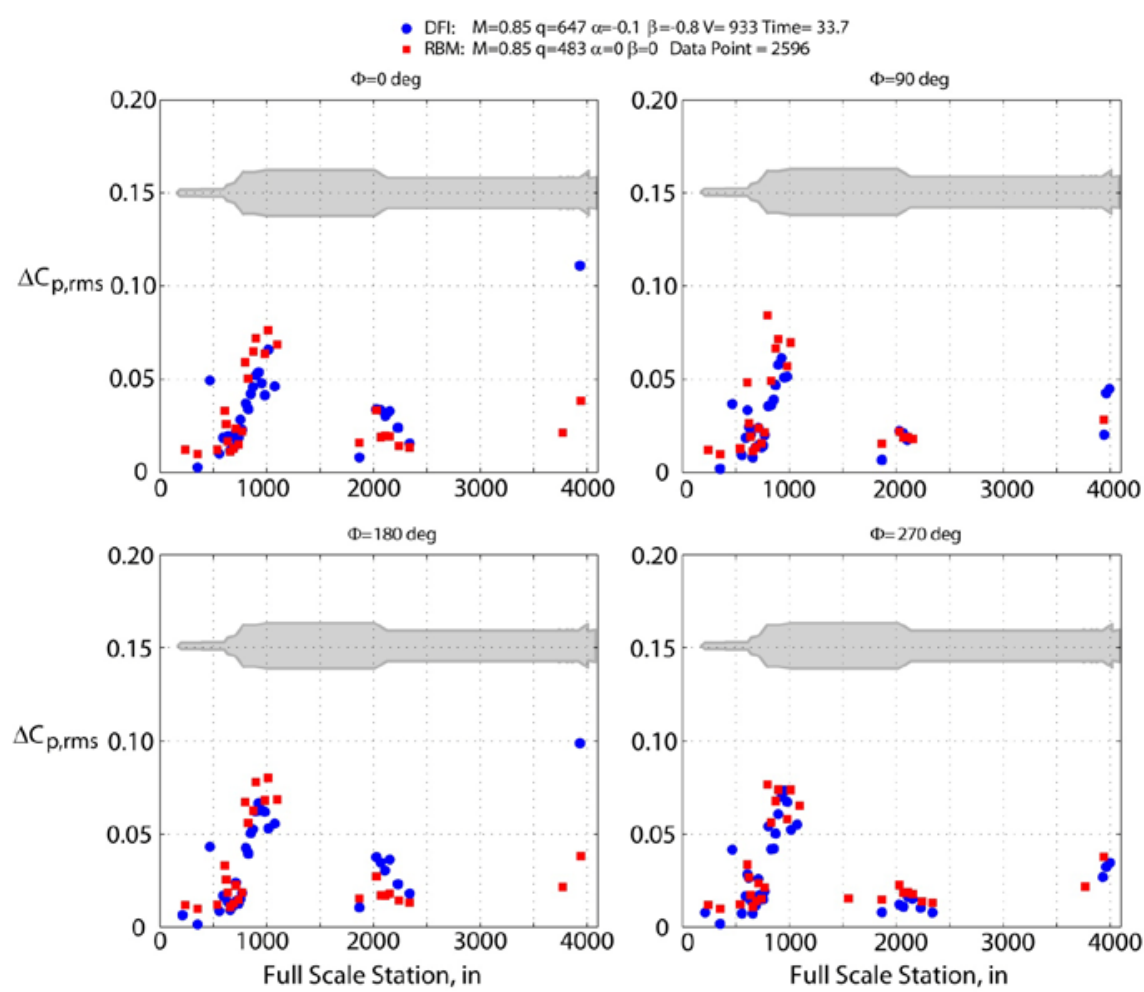

Figure 9. Comparison of DFI and RBM $\Delta C_{p, r m s}$ values at $M=0.85$ for $\Phi=0^{\circ}$, $90^{\circ}, 1^{\circ}$, and $270^{\circ}$.
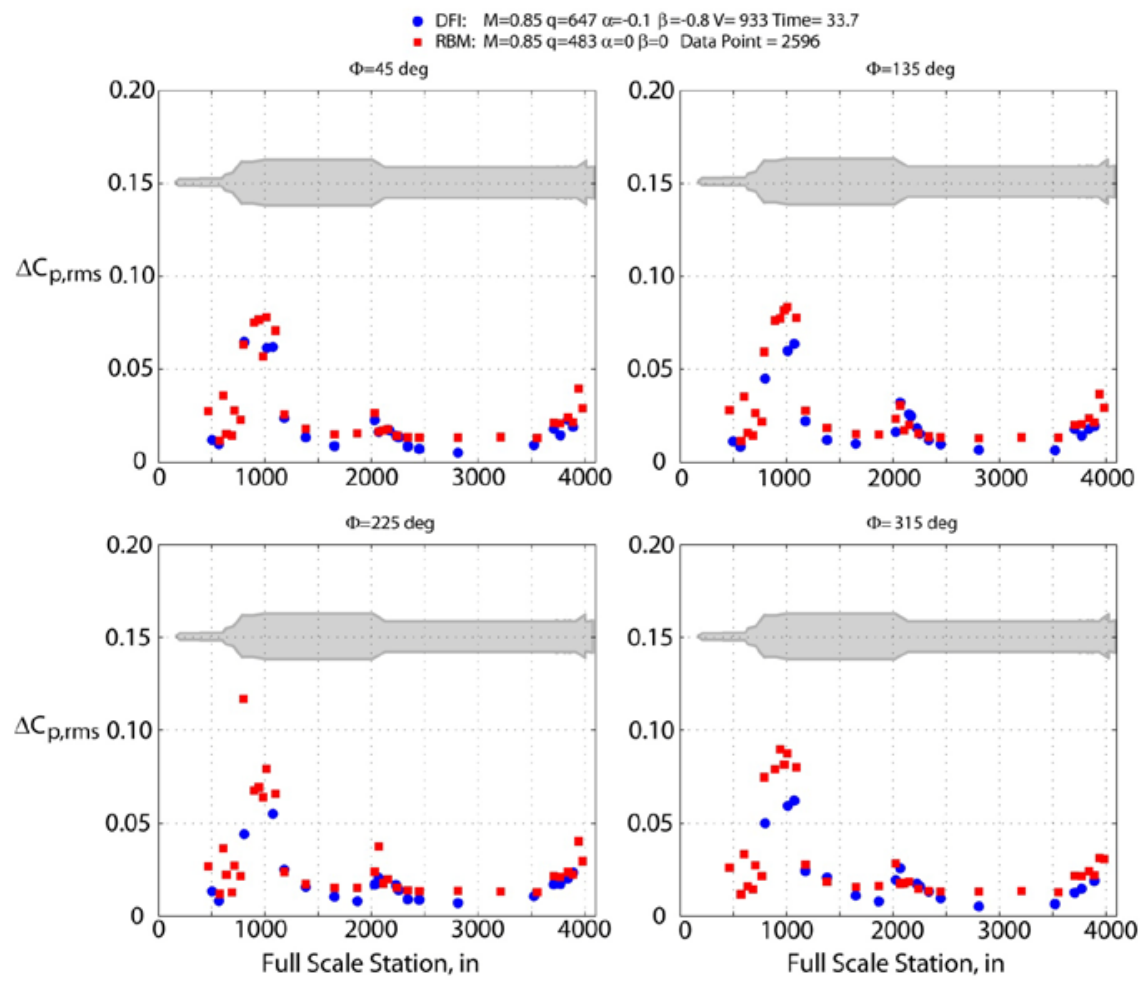

Figure 10. Comparison of DFI and RBM $\Delta C_{p, r m s}$ values at $M=0.85$ for $\Phi=45^{\circ}$, $135^{\circ}, 225^{\circ}$, and $315^{\circ}$. 

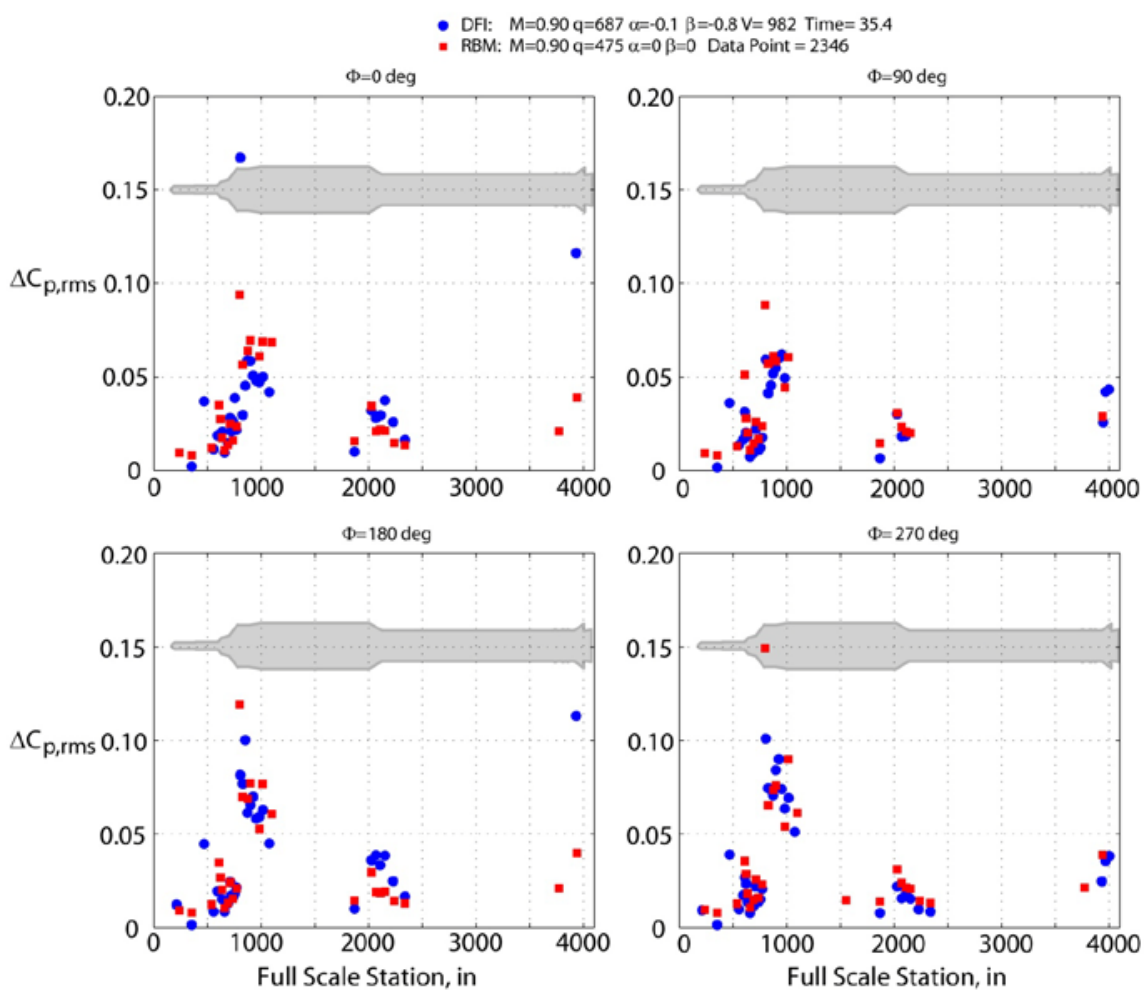

Figure 11. Comparison of DFI and RBM $\Delta C_{p, r m s}$ values at $M=0.90$ for $\Phi=$ $0^{\circ}, \mathbf{9 0}^{\circ}, \mathbf{1 8 0}^{\circ}$, and $270^{\circ}$.
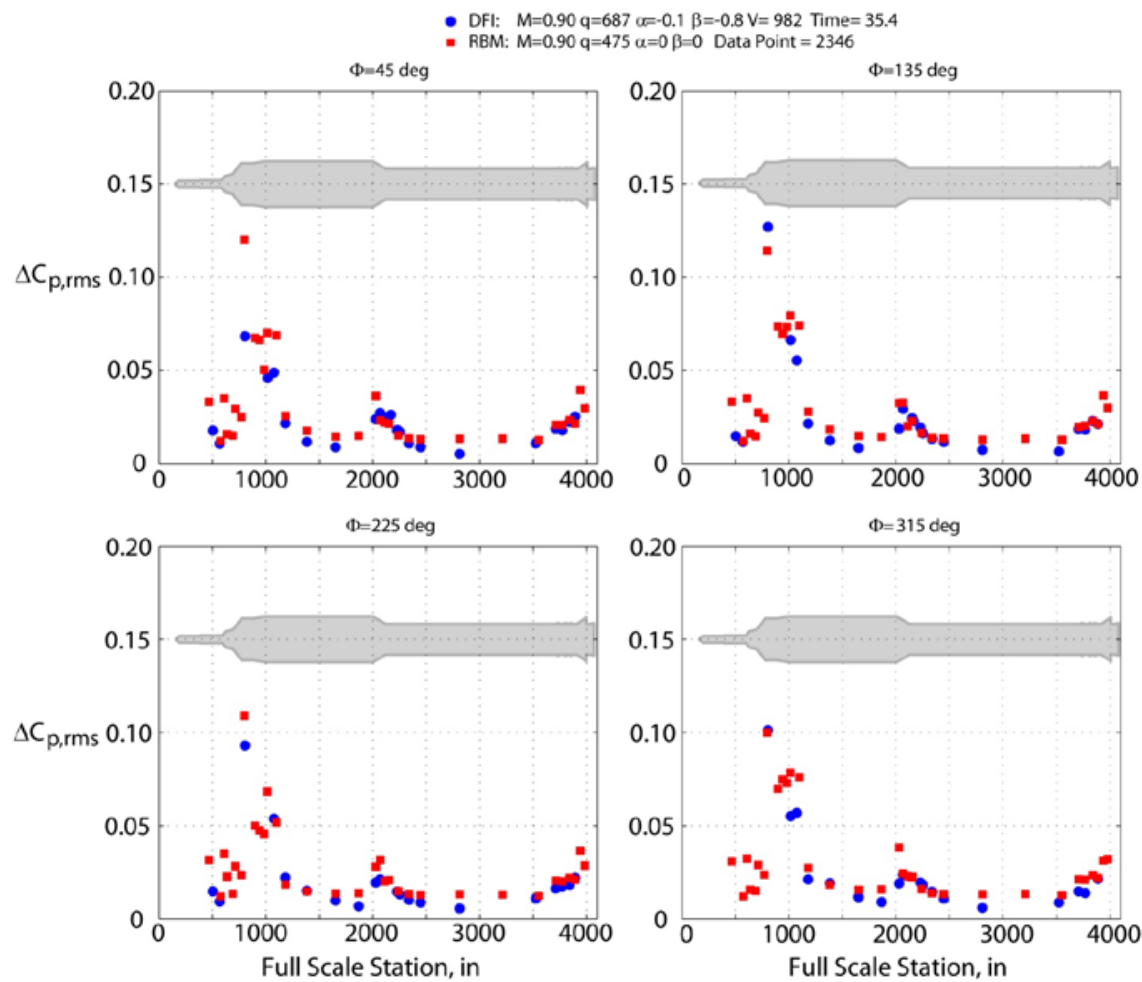

Figure 12. Comparison of DFI and RBM $\Delta C_{p, r m s}$ values at $M=0.90$ for $\Phi=$ $45^{\circ}, 135^{\circ}, 225^{\circ}$, and $315^{\circ}$. 

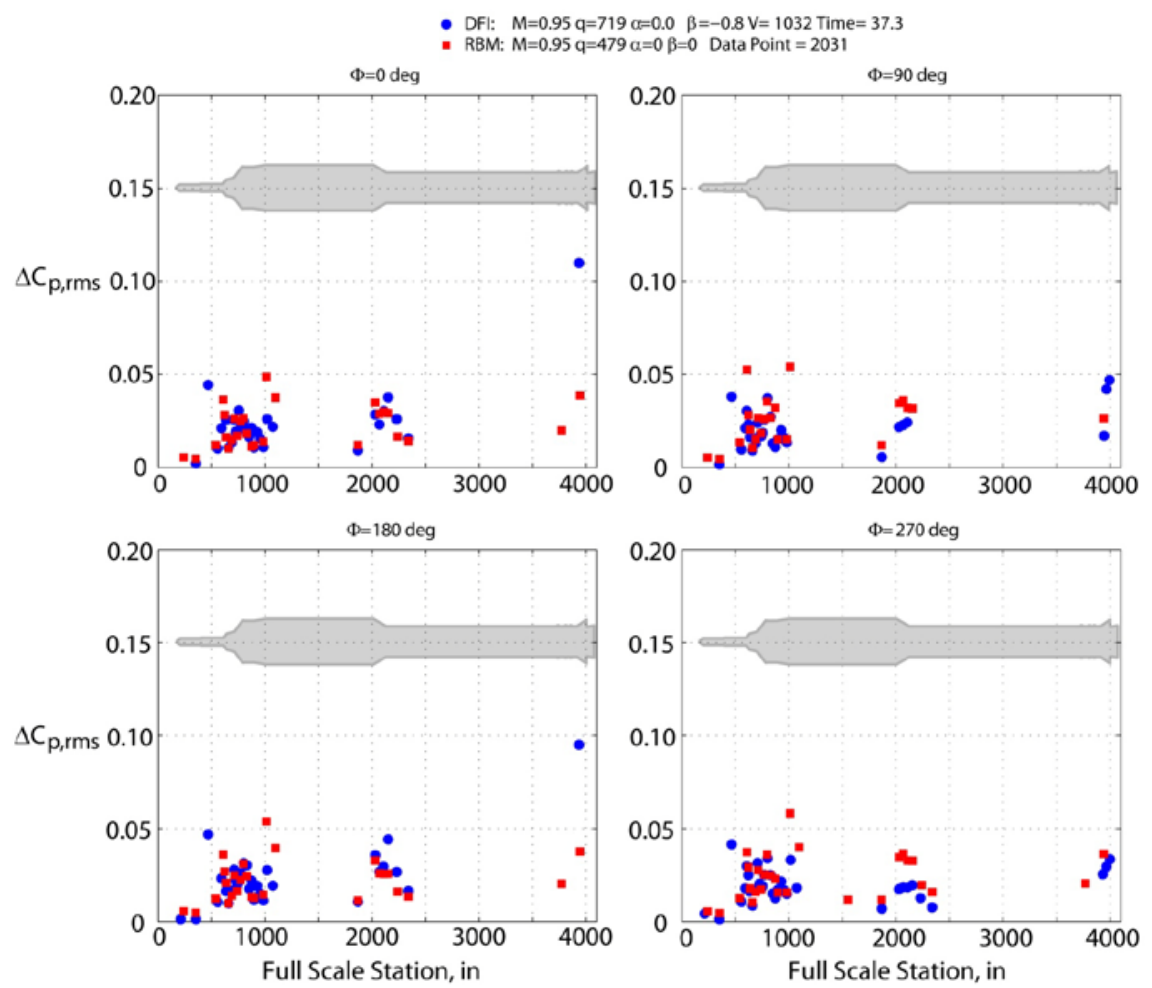

Figure 13. Comparison of DFI and RBM $\Delta C_{p, r m s}$ values at $M=0.95$ for $\Phi=0^{\circ}$, $90^{\circ}, 180^{\circ}$, and $270^{\circ}$.
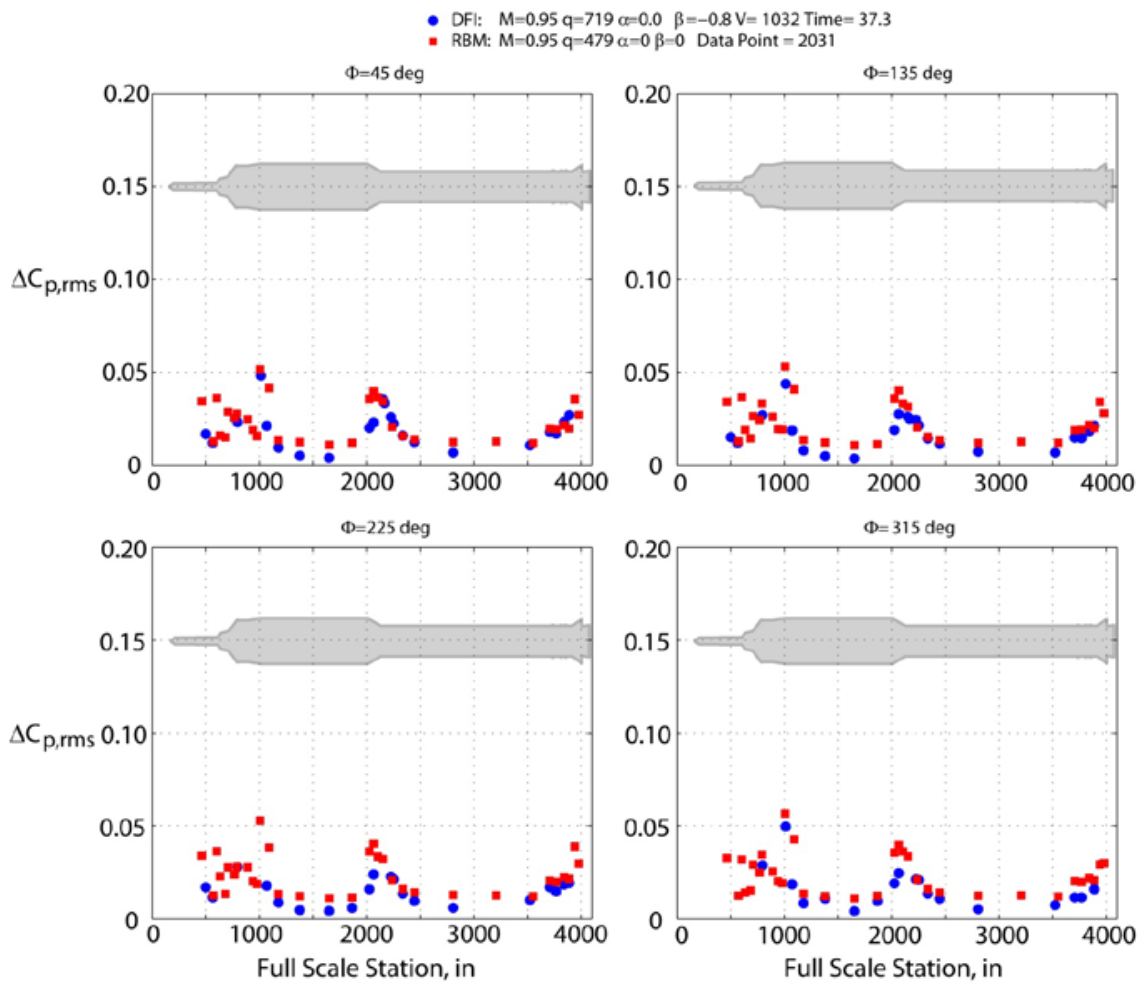

Figure 14. Comparison of DFI and RBM $\Delta C_{p, r m s}$ values at $M=0.95$ for $\Phi=45^{\circ}$, $135^{\circ}, 225^{\circ}$, and $315^{\circ}$. 

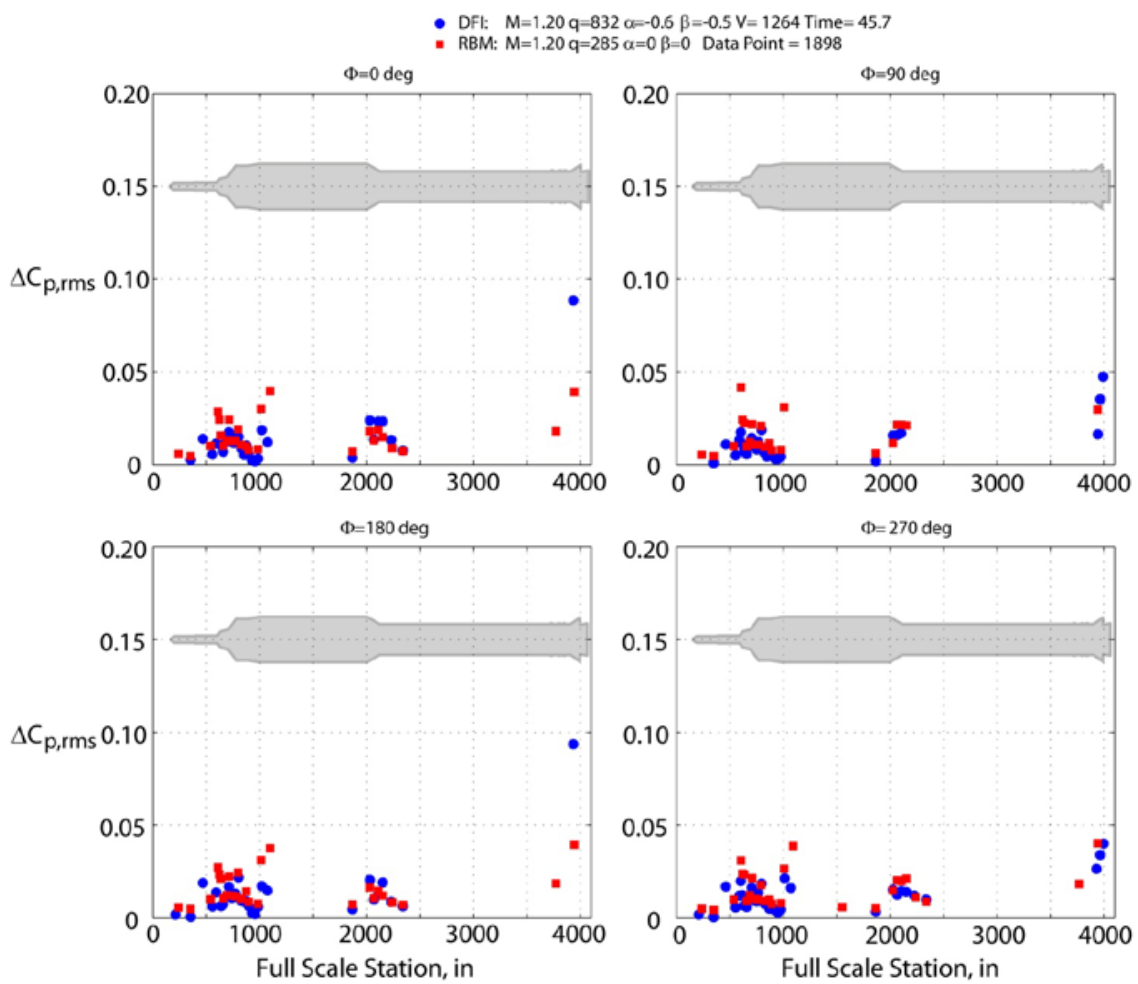

Figure 15. Comparison of DFI and RBM $\Delta C_{p, r m s}$ values at $M=1.20$ for $\Phi=$ $0^{\circ} .90^{\circ} \cdot 180^{\circ}$. and $270^{\circ}$.
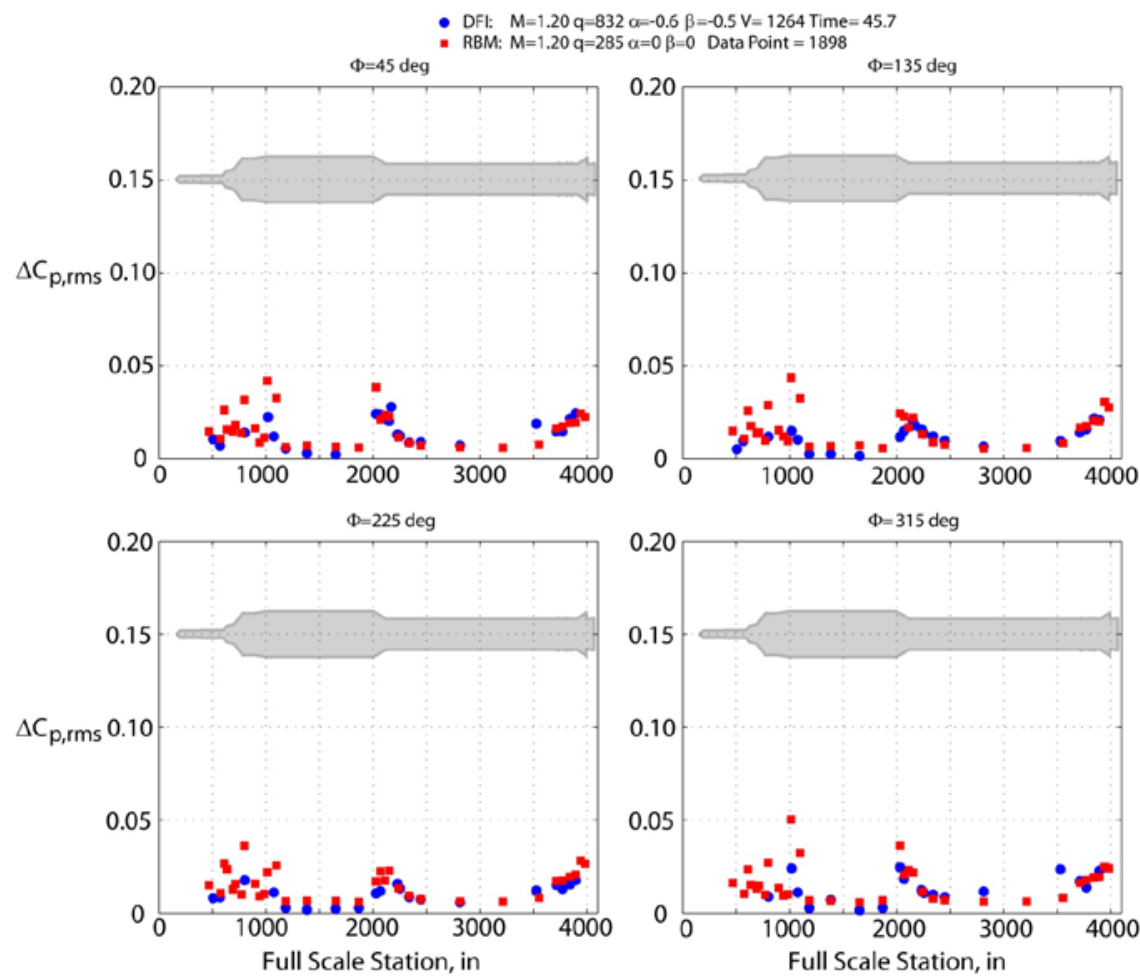

Figure 16. Comparison of DFI and RBM $\Delta C_{p, r m s}$ values at $M=1.20$ for $\Phi=45^{\circ}$, $135^{\circ}, 225^{\circ}$, and $315^{\circ}$. 

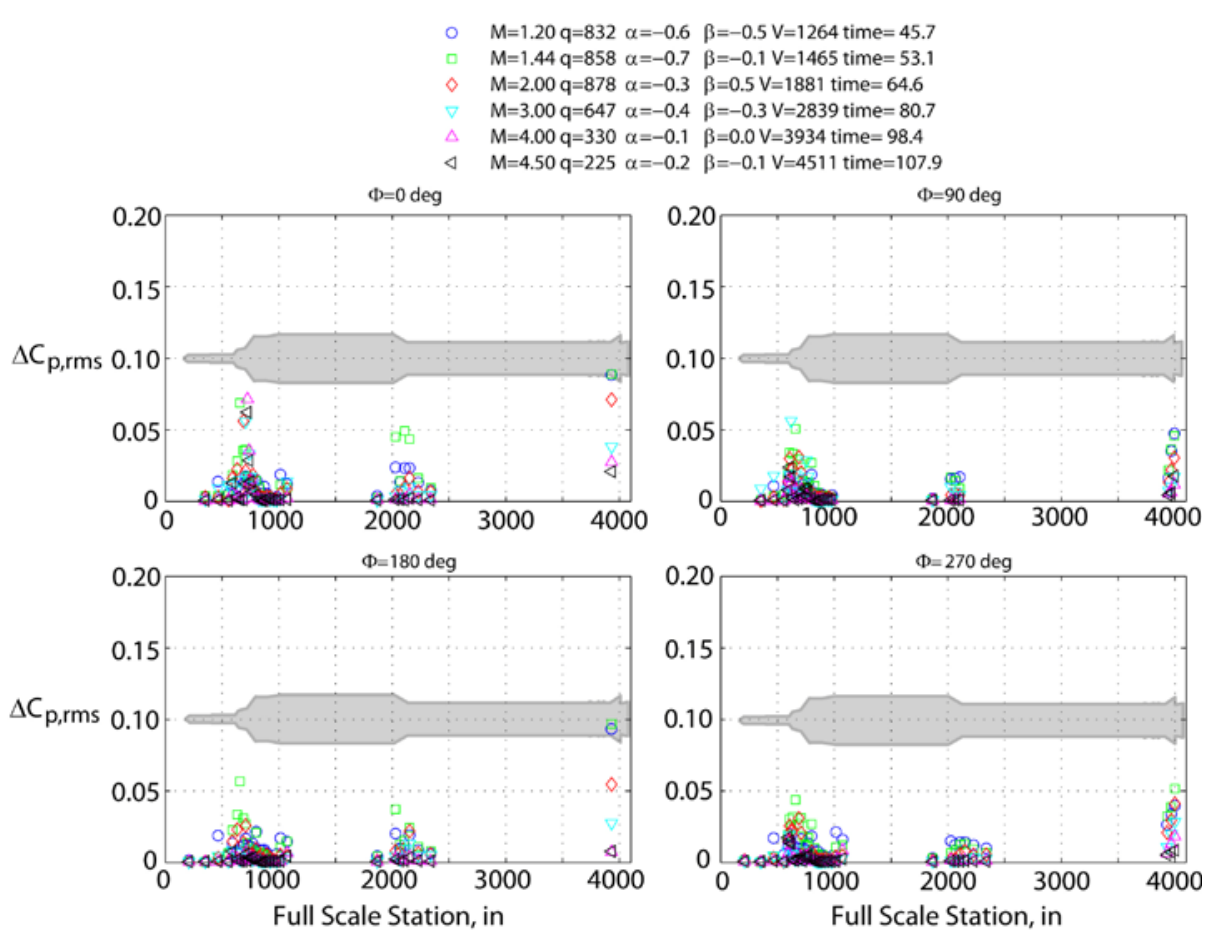

Figure 17. DFI $\Delta C_{p, r m s}$ values at $M=1.20,1.44,2.00,3.00,4.00$, and 4.50 for $\Phi=0^{\circ} .90^{\circ} .180^{\circ}$. and $270^{\circ}$.
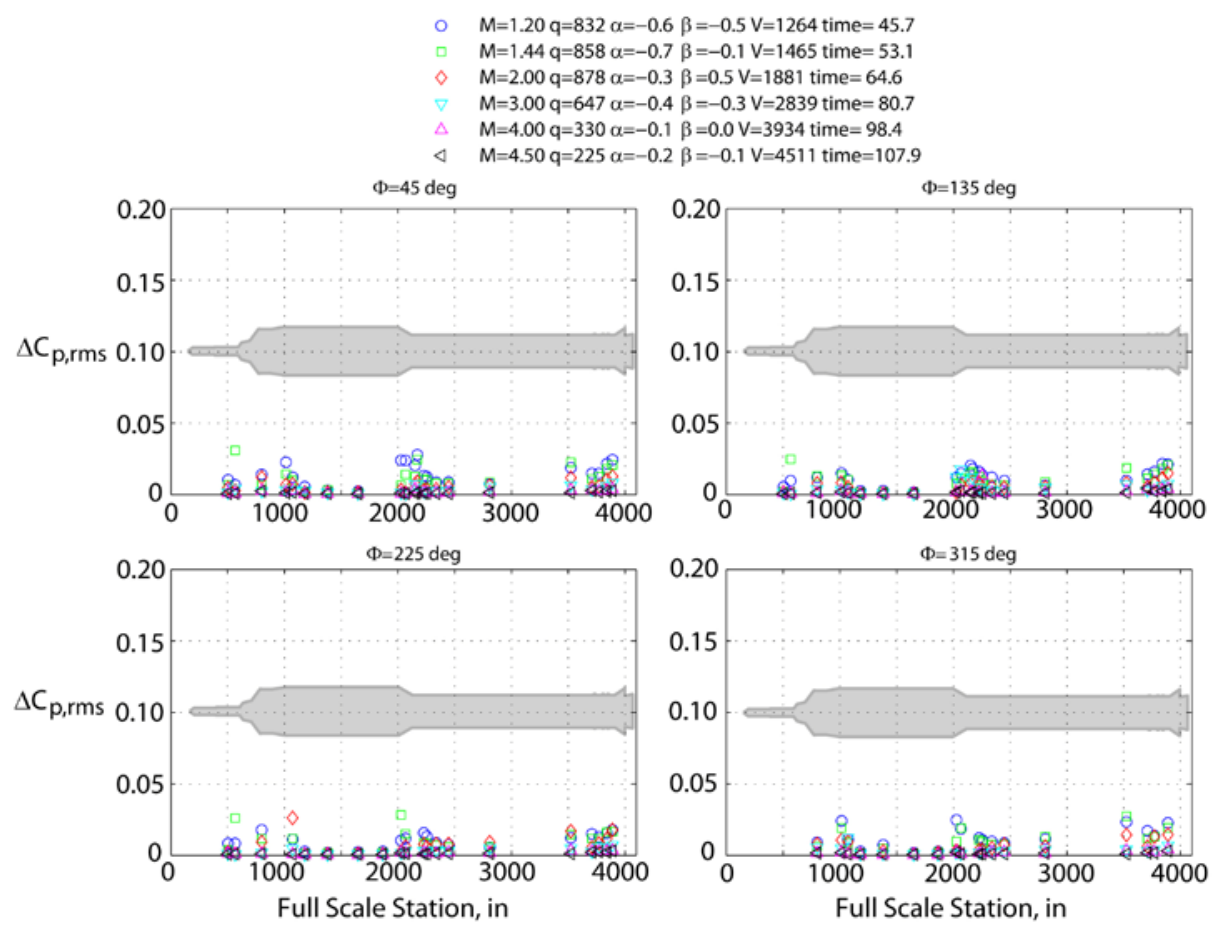

Figure 18. DFI $\Delta C_{p, r m s}$ values at $M=1.20,1.44,2.00,3.00,4.00$, and 4.50 for $\Phi=45^{\circ}, 135^{\circ}, 225^{\circ}$, and $315^{\circ}$. 

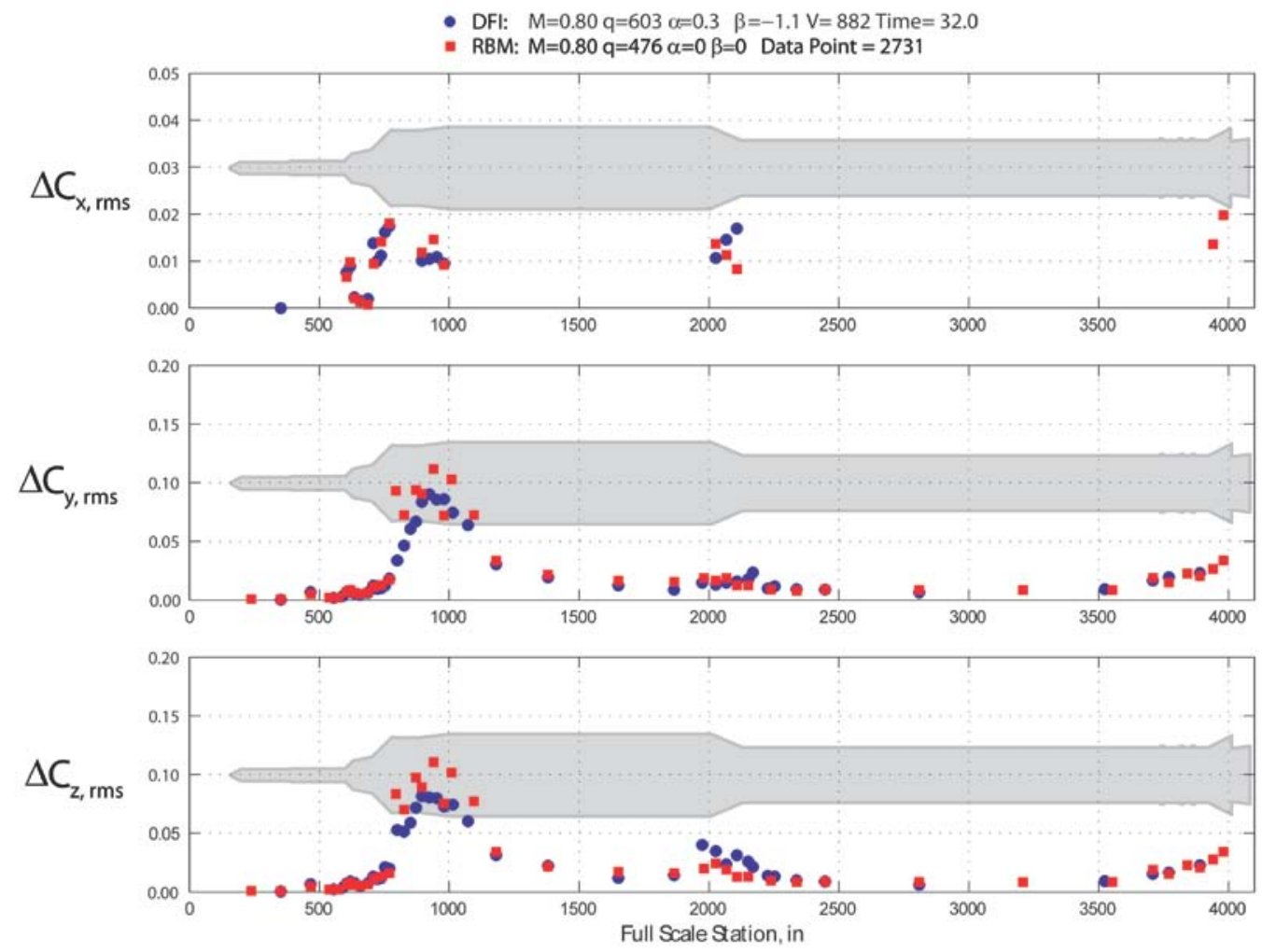

Figure 19. Comparison of DFI and RBM sectional buffet forcing function root-mean-square trends for Mach 0.80.
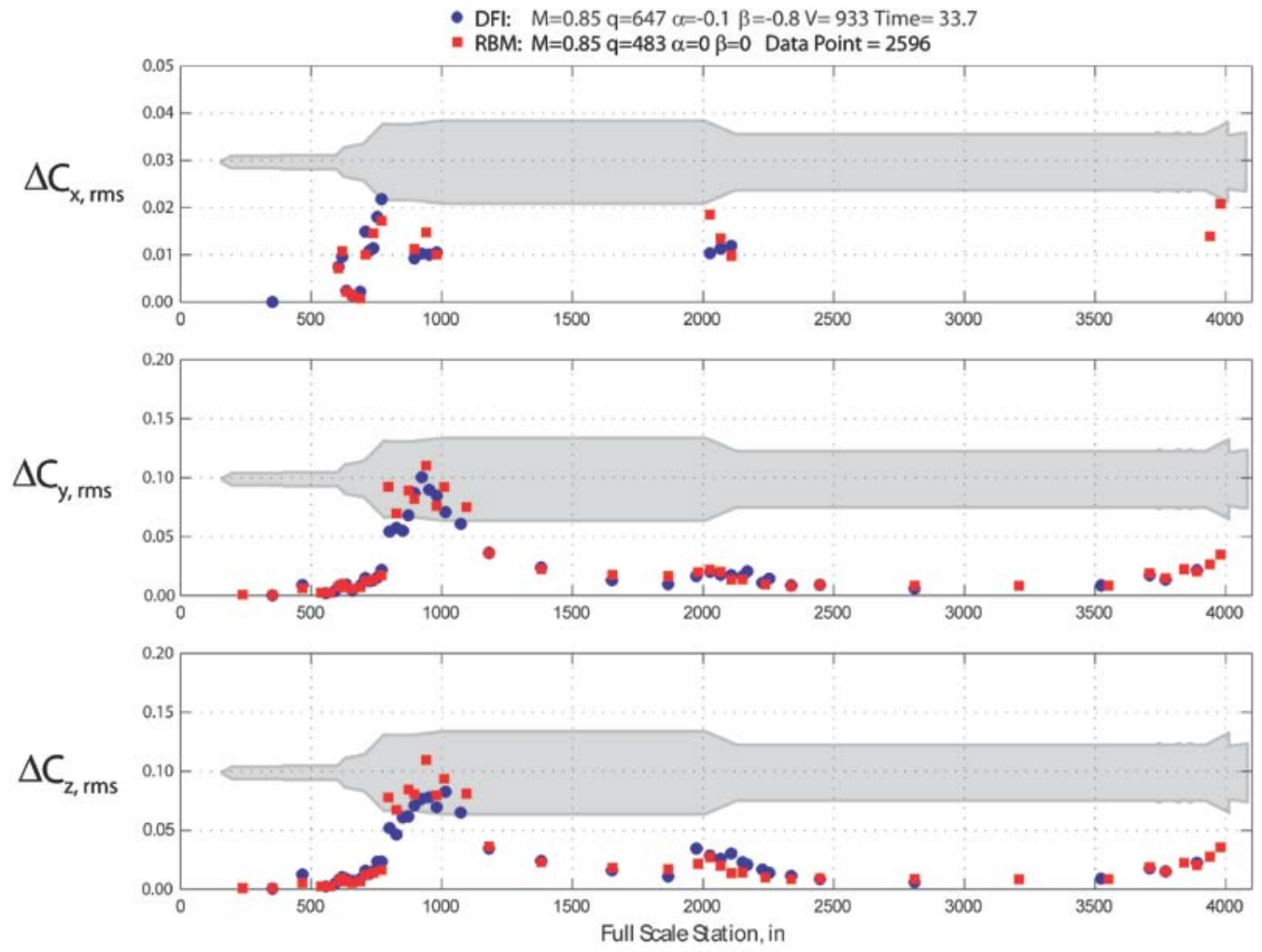

Figure 20. Comparison of DFI and RBM sectional buffet forcing function root-mean-square trends for Mach 0.85. 

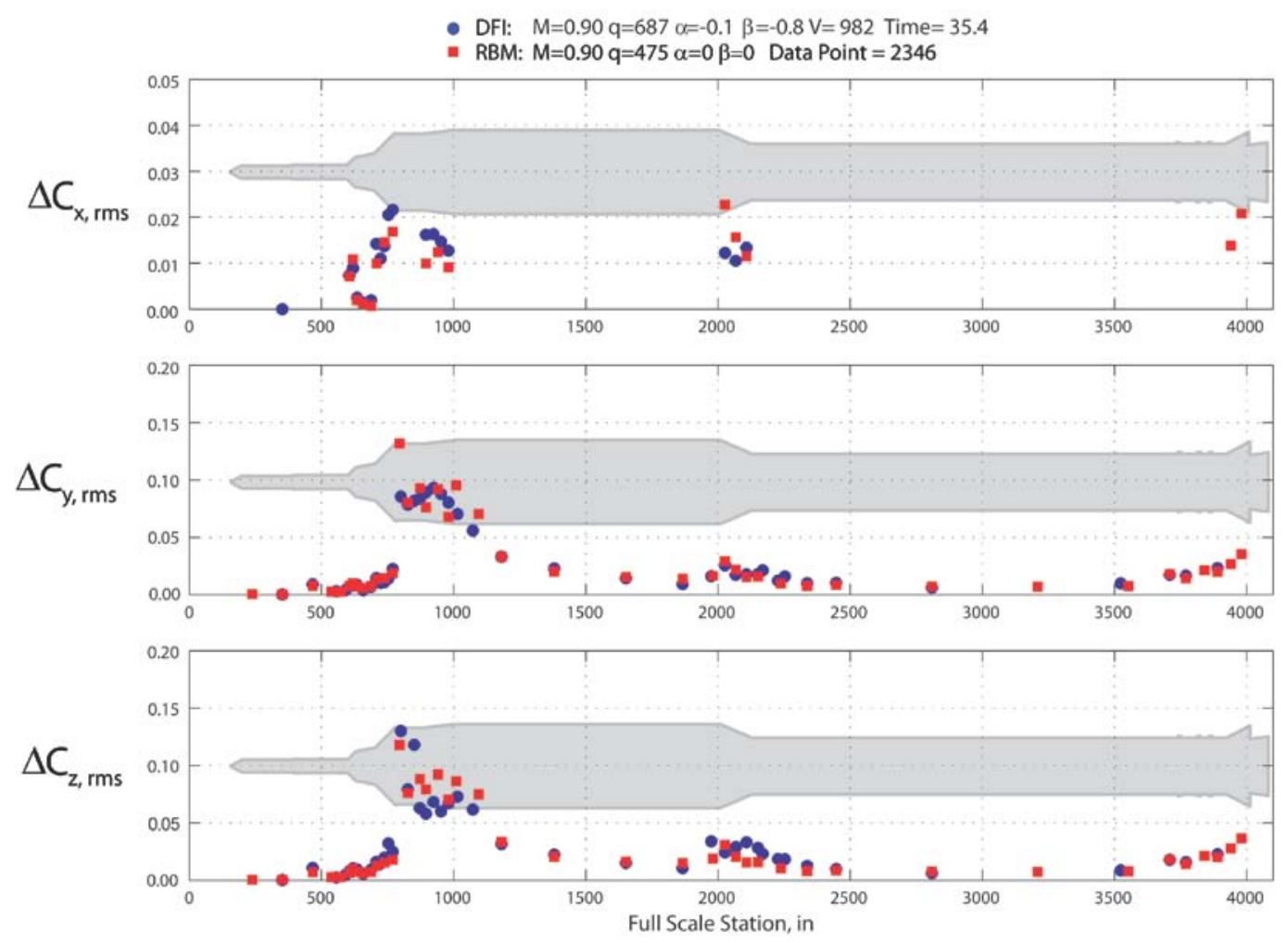

Figure 21. Comparison of DFI and RBM sectional buffet forcing function root-mean-square trends for Mach 0.90.
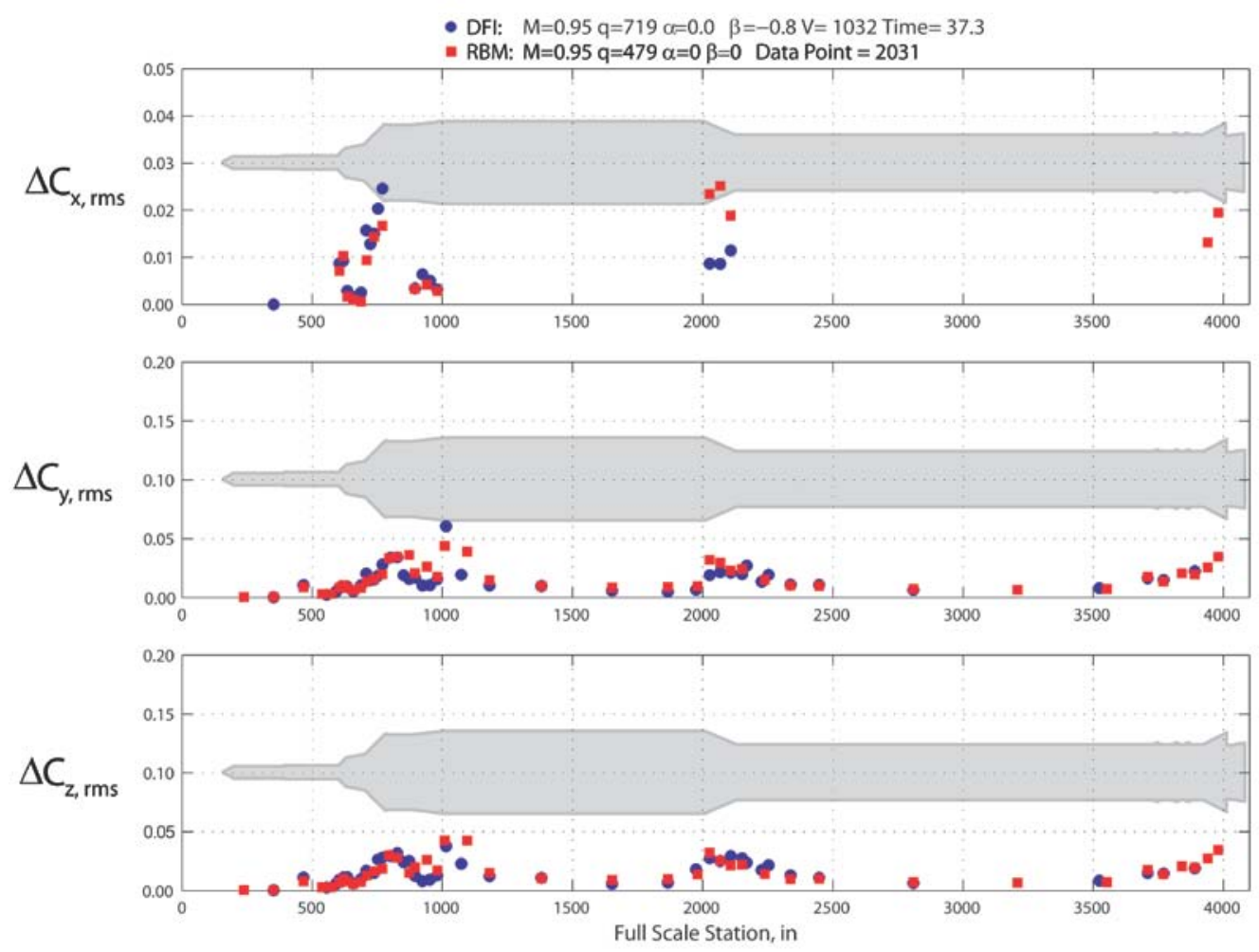

Figure 22. Comparison of DFI and RBM sectional buffet forcing function root-mean-square trends for Mach 0.95.

18

American Institute of Aeronautics and Astronautics 

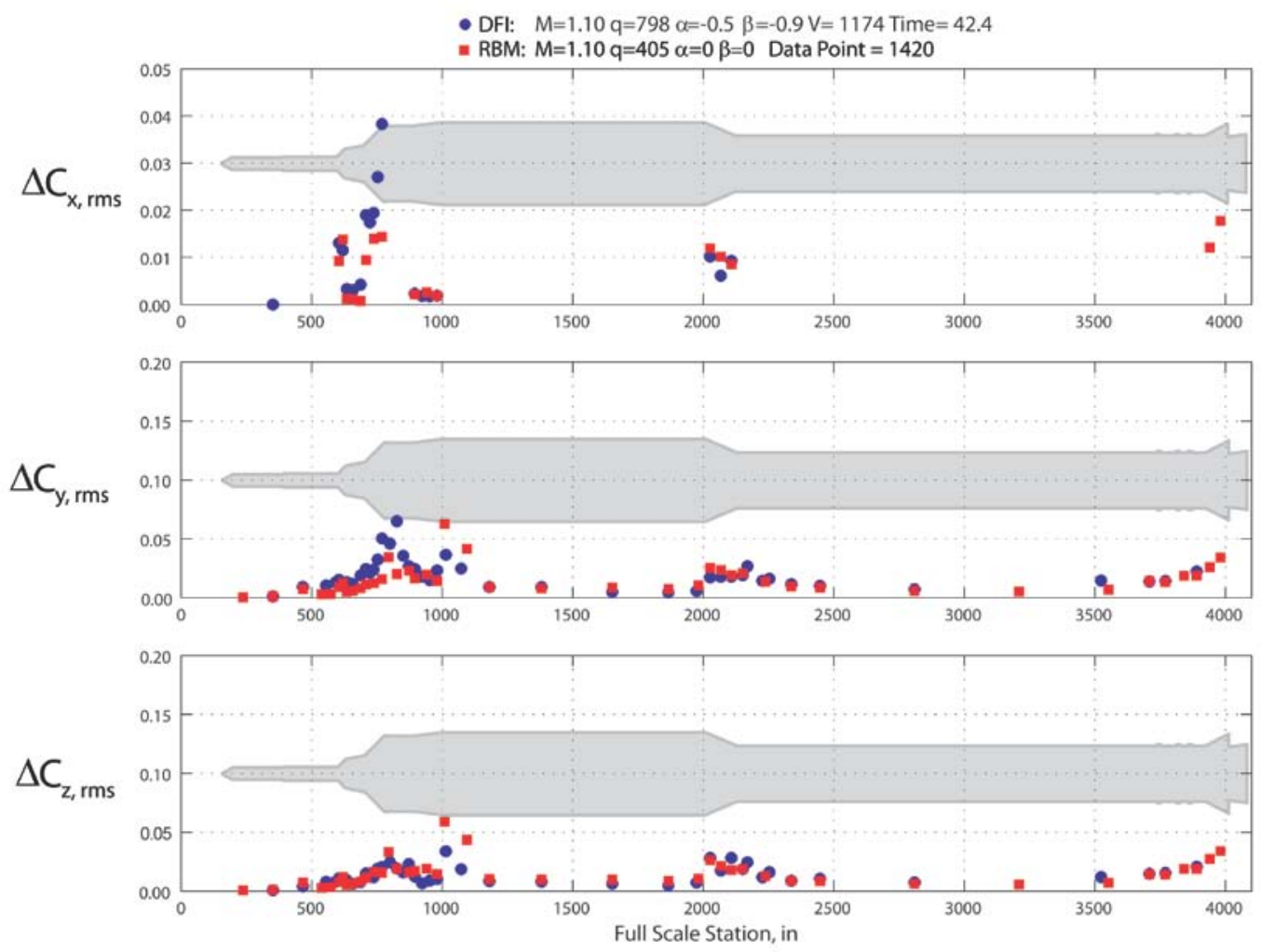

Figure 23. Comparison of DFI and RBM sectional buffet forcing function root-mean-square trends for Mach 1.10.
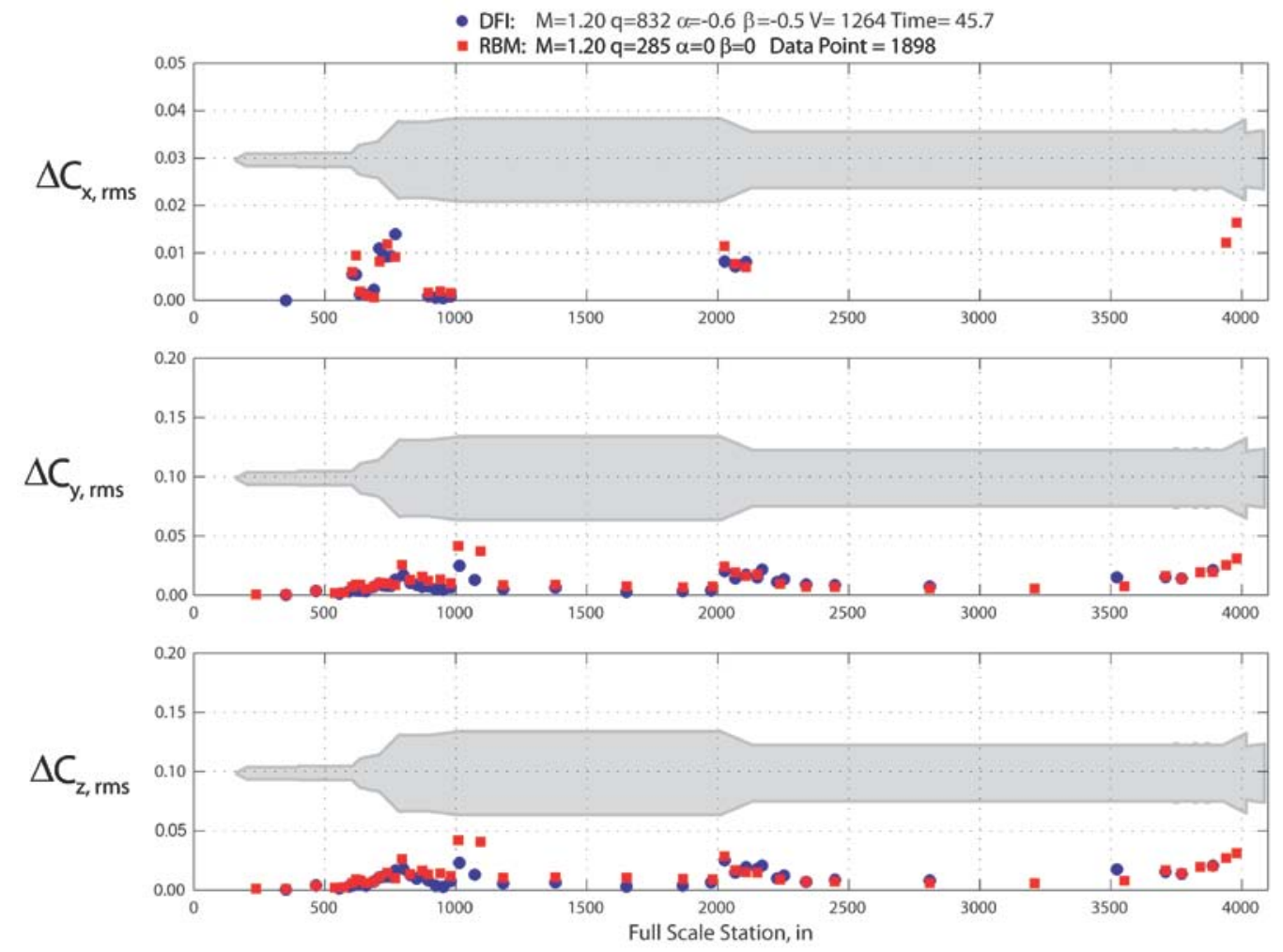

Figure 24. Comparison of DFI and RBM sectional buffet forcing function root-mean-square trends for Mach 1.20.

19

American Institute of Aeronautics and Astronautics 

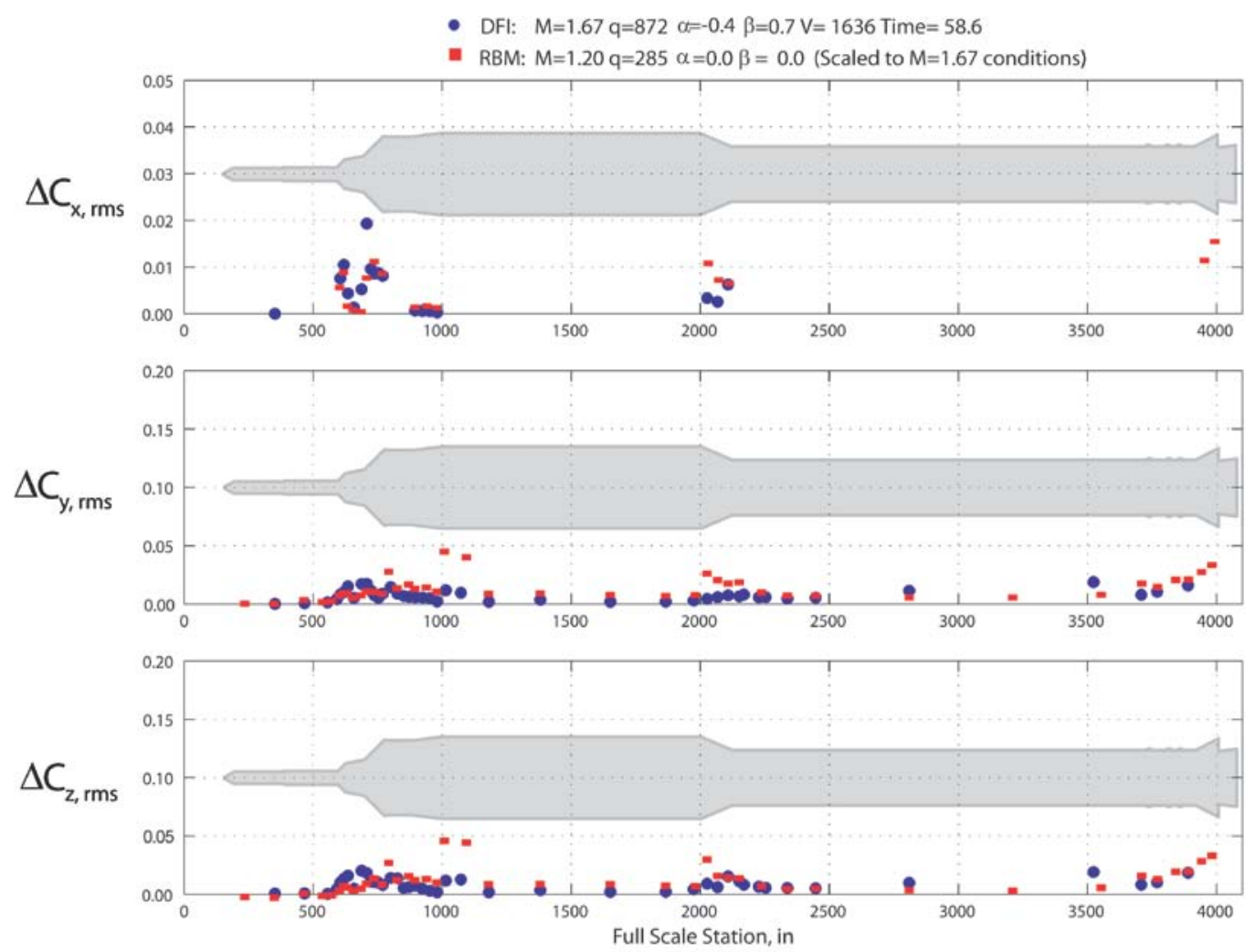

Figure 25. Comparison of DFI and RBM sectional buffet forcing function root-mean-square trends for Mach 1.67 (near maximum dynamic pressure).

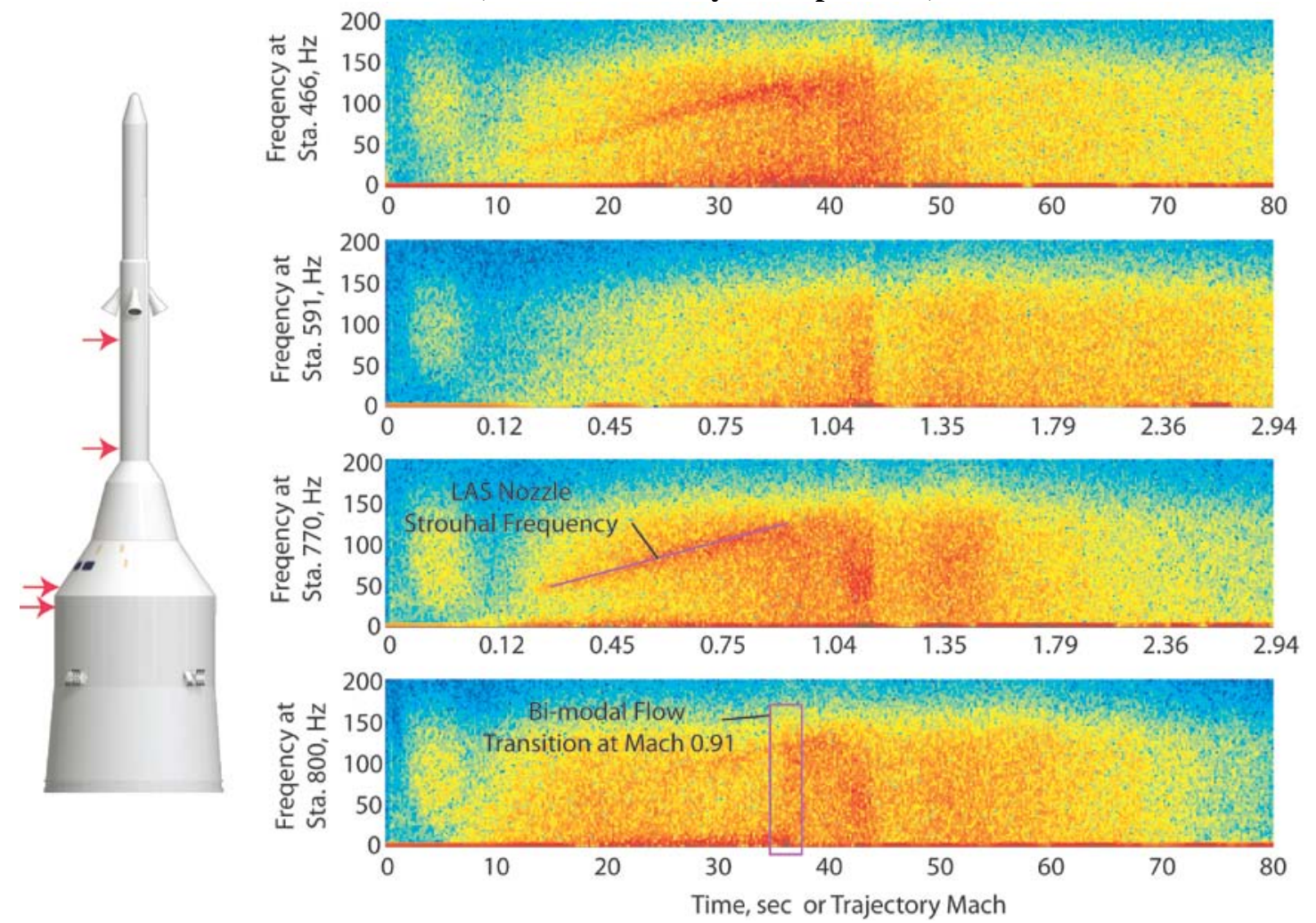

Figure 26. Section buffet forcing function spectrograms for stations 466, 591, 770, and 800. 

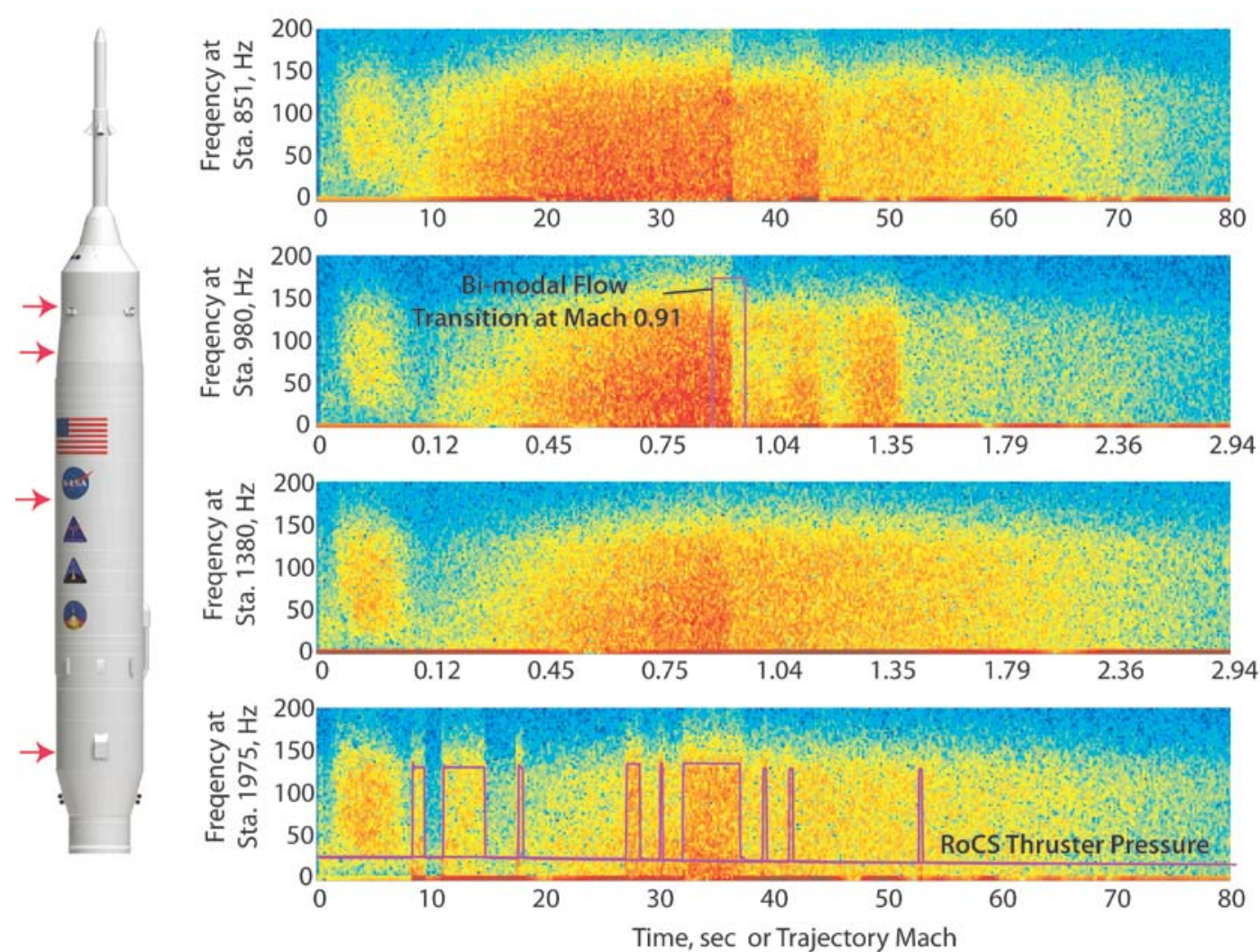

Figure 27. Section buffet forcing function spectrograms for stations 851. 980, 1380, 1975.
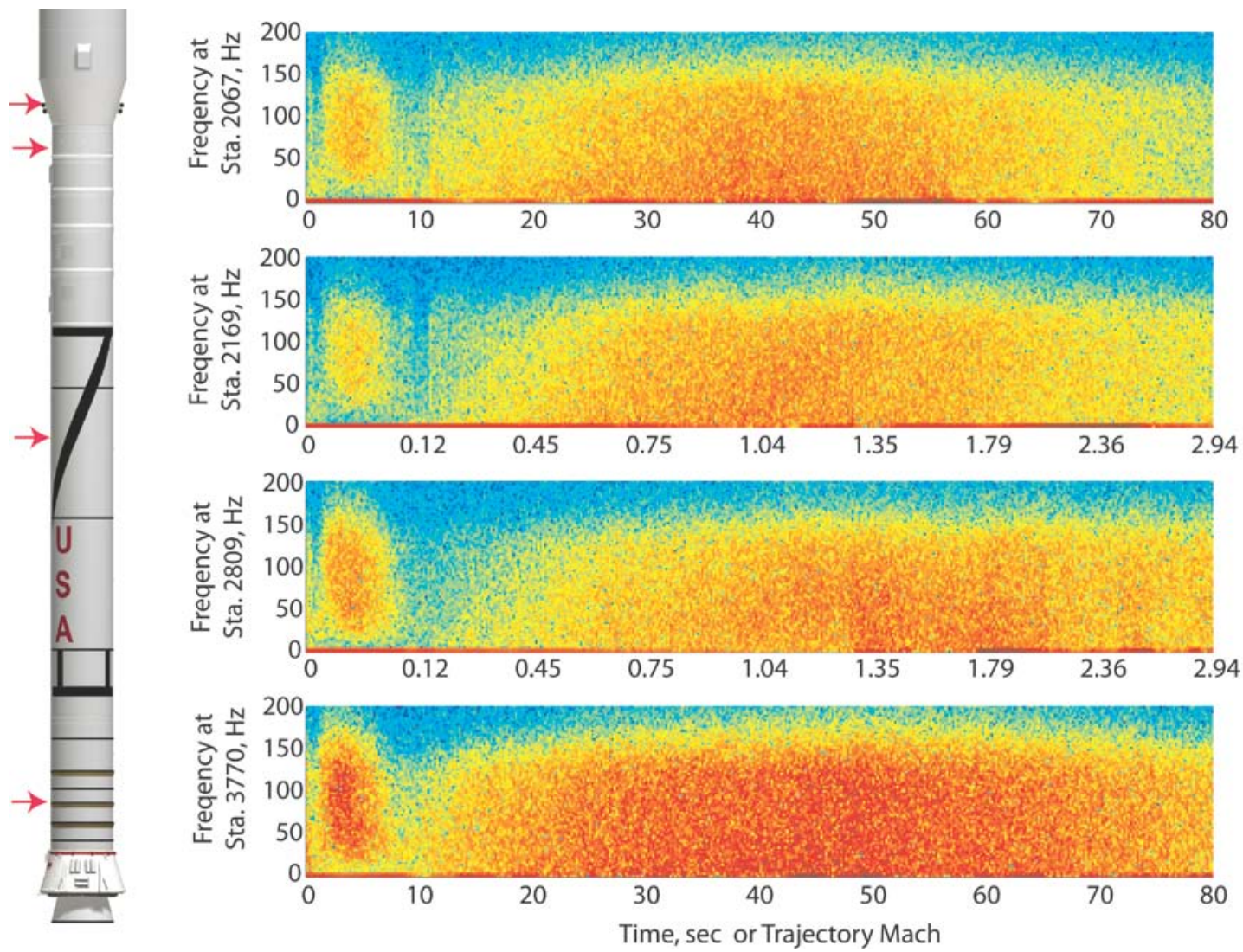

Figure 28. Section buffet forcing function spectrograms for stations 2067, 2169, 2809, 3770.

21

American Institute of Aeronautics and Astronautics 

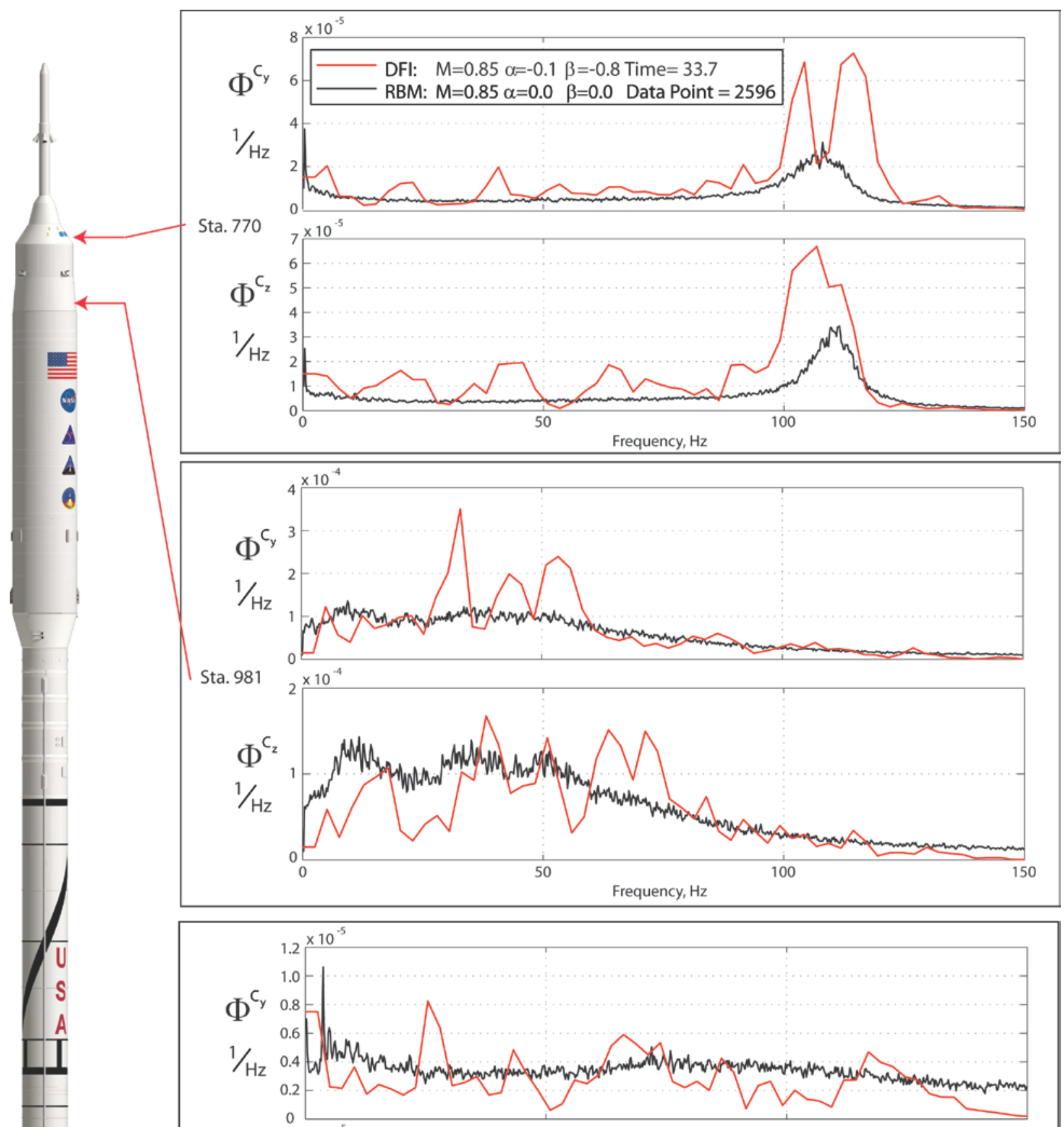

Sta. 3770

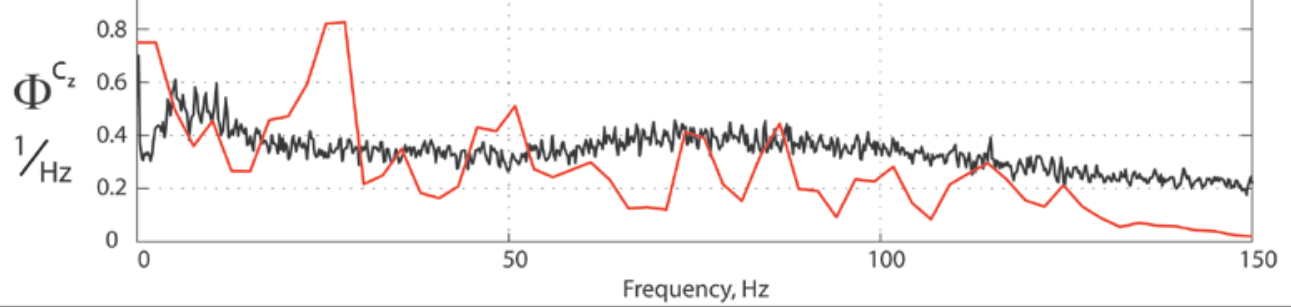

Figure 29. Comparison of FTV and RBM sectional forcing function power spectral densities at Mach 0.85 . 

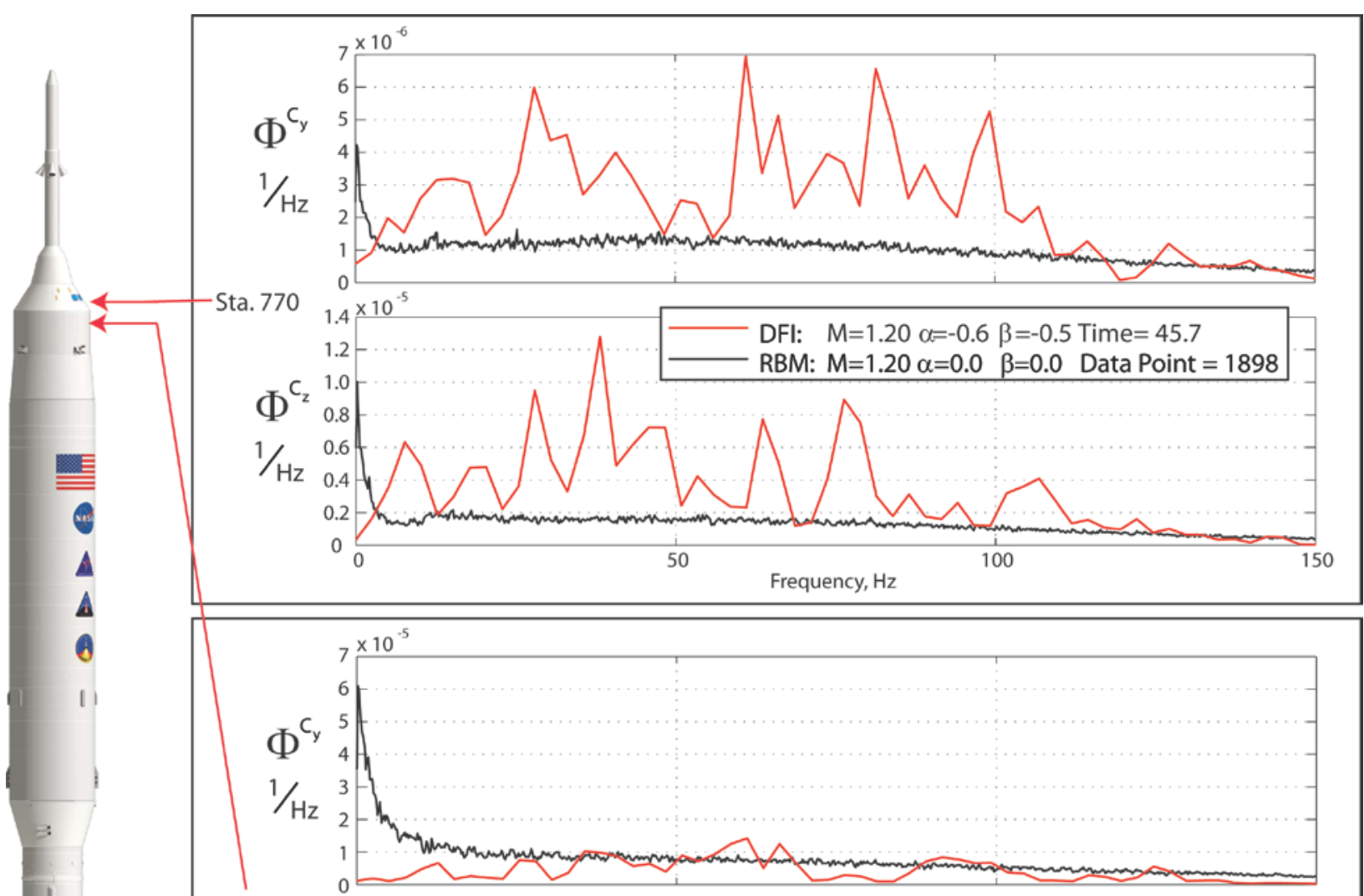

Sta. 800
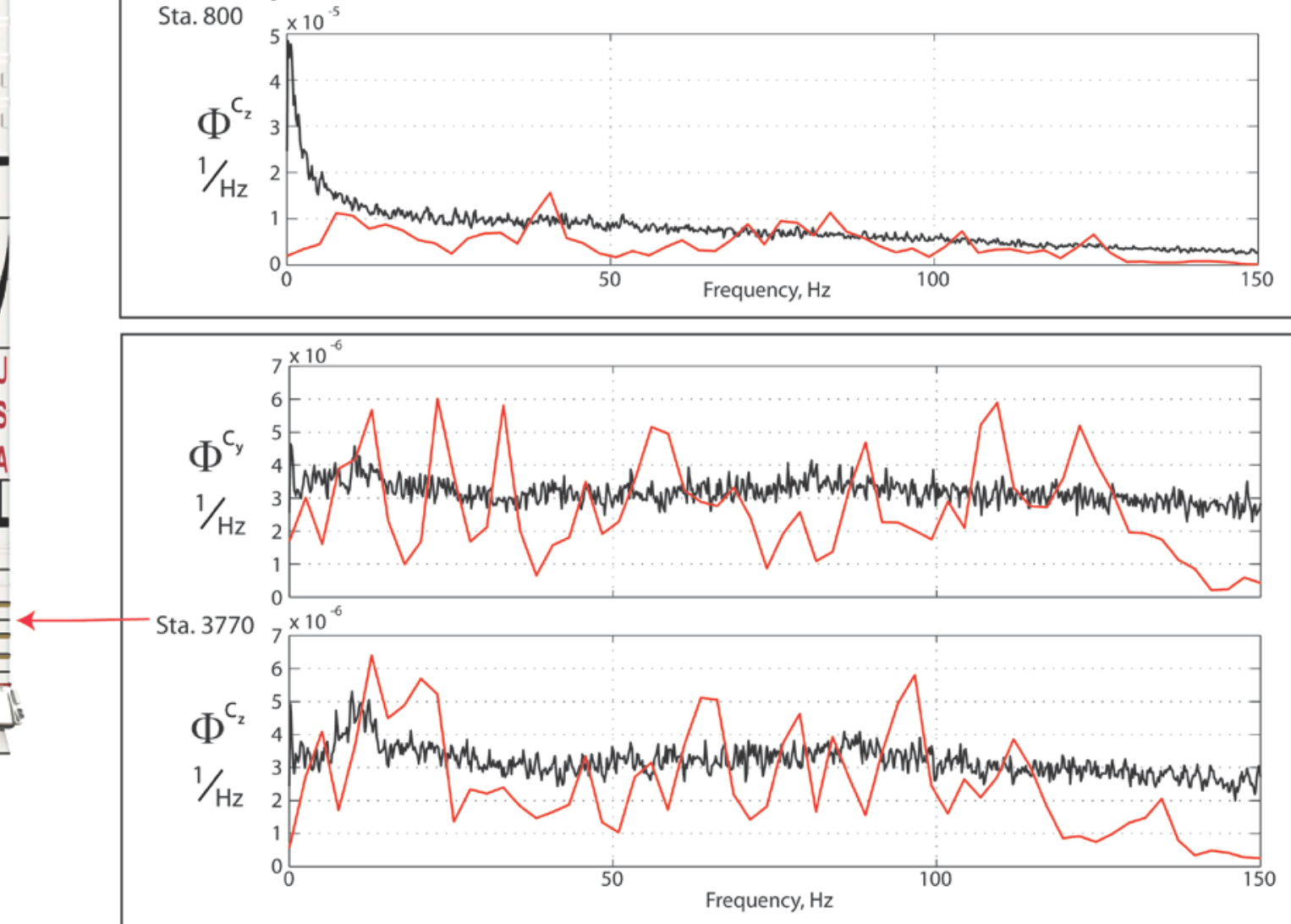

Figure 30. Comparison of FTV and RBM sectional forcing function power spectral densities at Mach 1.2.

American Institute of Aeronautics and Astronautics 


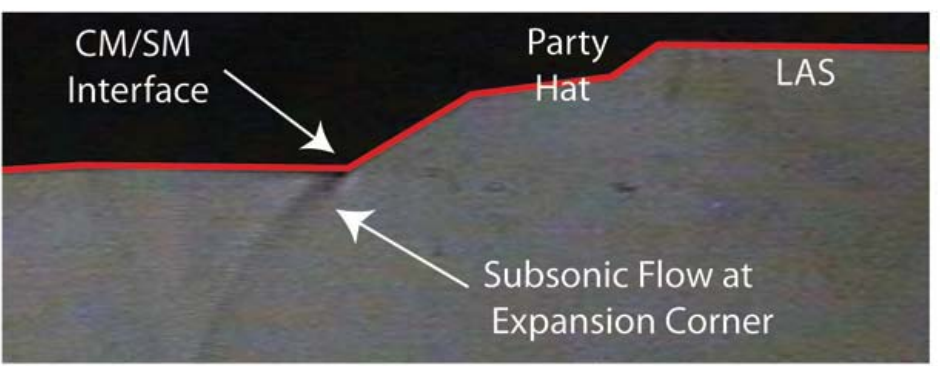

(a)

Expansion Corner

Alternating

Flow State \#1

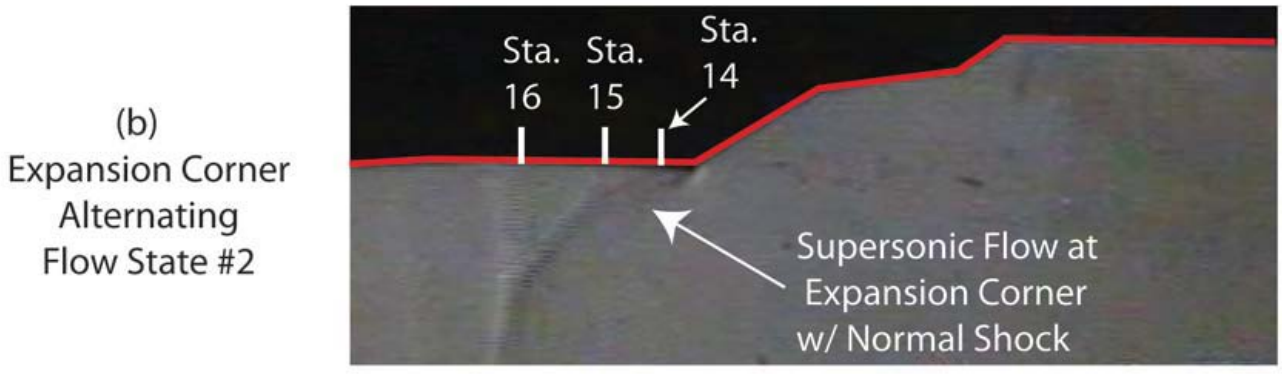

Figure 31. Shadowgraph of alternating flow conditions on RBM at Mach 0.90 .

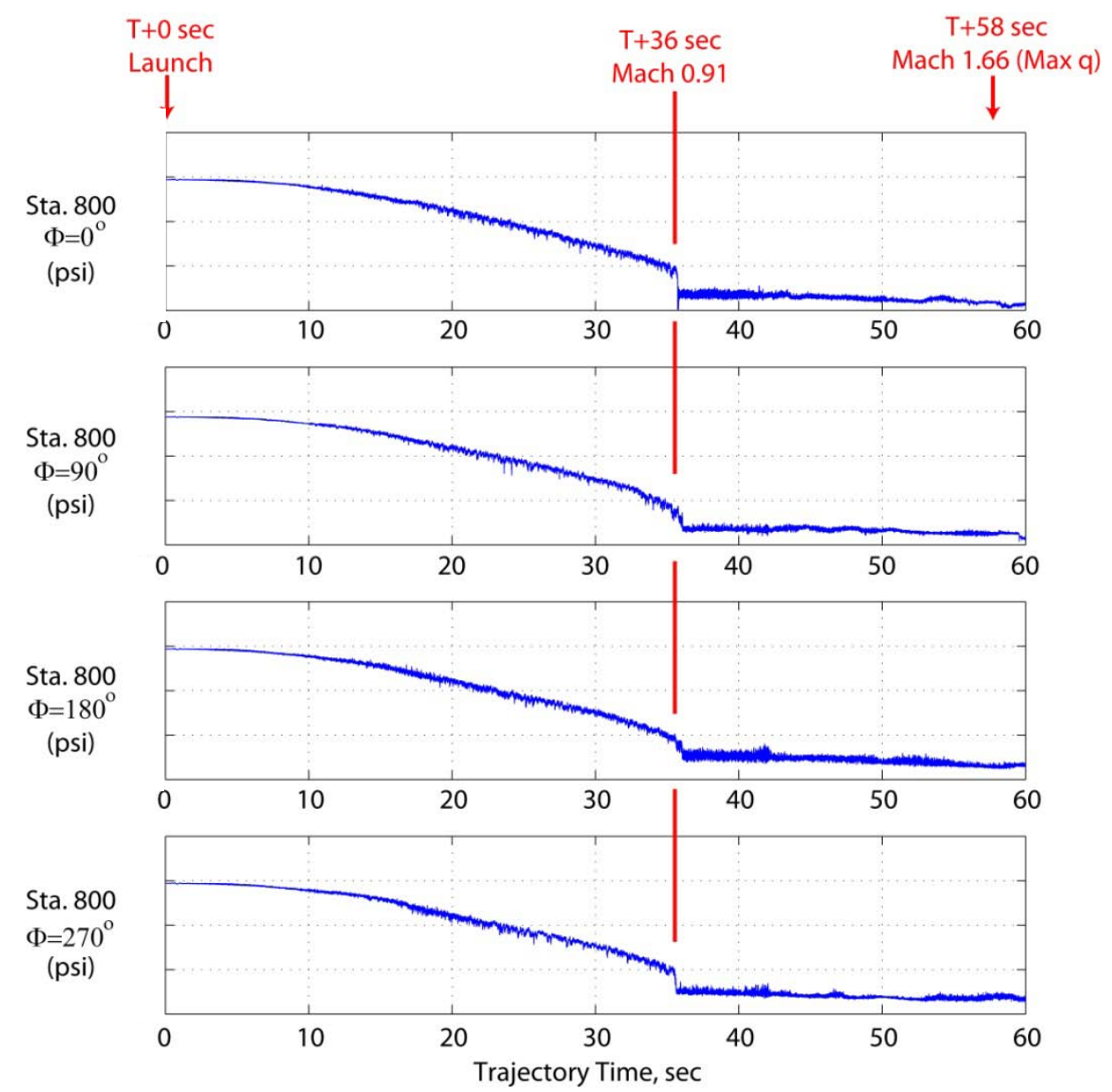

Figure 32. Ares I-X FTV pressure measurements at station 800 inches near cone-cylinder juction. 


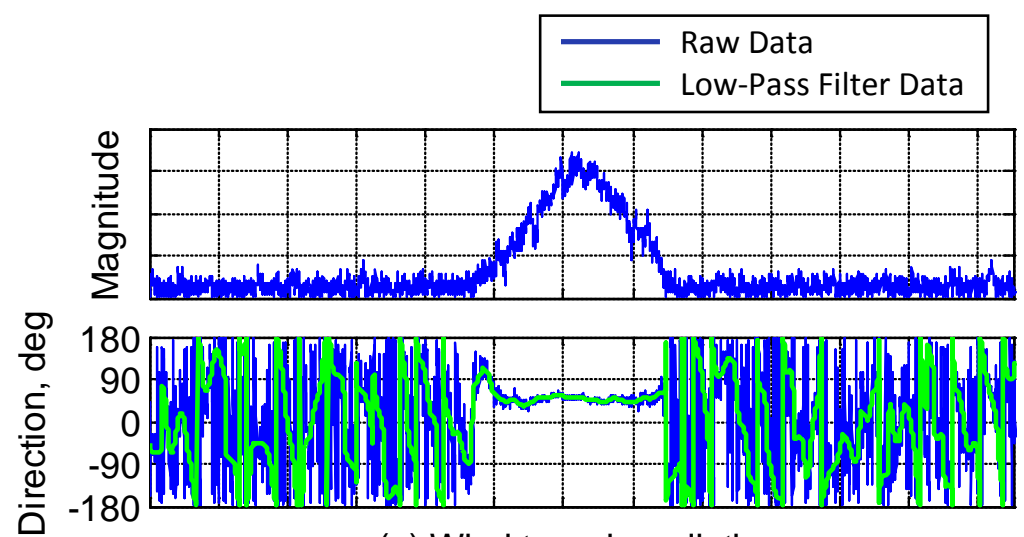

(a) Wind tunnel prediction

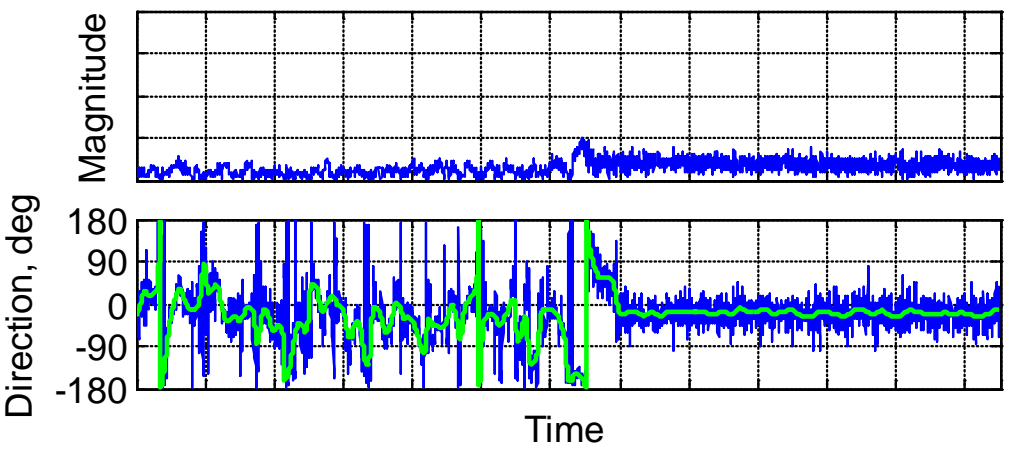

(b) Flight test data

Figure 33. Comparison of transonic alternating flow condition loads from RBM and FTV. 